\title{
Structural Characterization of Mesoporous Thin Film Architectures: A Tutorial Overview
}

\author{
Alberto Alvarez-Fernandez, Barry Reid, Maximiliano J. Fornerod, Alaric Taylor, Giorgio Divitini, \\ and Stefan Guldin*
}

Cite This: ACS Appl. Mater. Interfaces 2020, 12, 5195-5208

Read Online

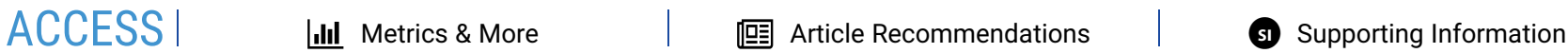

ABSTRACT: Mesoporous thin film architectures are an important class of materials that exhibit unique properties, which include high surface area, versatile surface functionalization, and bicontinuous percolation paths through a broad library of pore arrangements on the $10 \mathrm{~nm}$ length scale. Although porosimetry of bulk materials via sorption techniques is common practice, the characterization of thin mesoporous films with small sample volumes remains a challenge. A range of techniques are geared toward providing information over pore morphology, pore size distribution, surface area and overall porosity, but none of them offers a holistic evaluation and results are at times

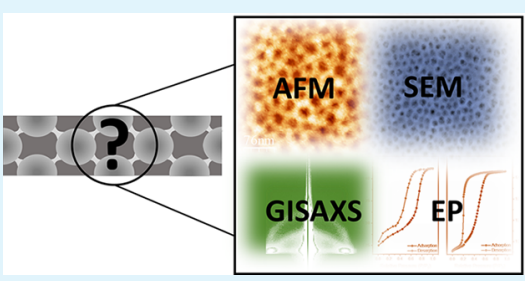
inconsistent. In this work, we present a tutorial overview for the reliable structural characterization of mesoporous films. Three model samples with variable pore size and porosity prepared by block copolymer (BCP) coassembly serve for a rational comparison. Various techniques are assessed side-by-side, including scanning electron microscopy (SEM), atomic force microscopy (AFM), grazing incidence small-angle X-ray scattering (GISAXS), and ellipsometric porosimetry (EP). We critically discuss advantages and limitations of each technique and provide guidelines for reliable implementation.

KEYWORDS: mesoporous, characterization, ellipsometric porosimetry, AFM, SEM, GISAXS, thin film, structure

\section{INTRODUCTION}

Mesoporous architectures with pore diameters in the range of $2-50 \mathrm{~nm}$ and film thicknesses up to $10 \mu \mathrm{m}$ are promising components for a wide range of applications, such as gas and energy storage, ${ }^{1-3}$ separation and purification membranes, ${ }^{4-6}$ photovoltaics cells, ${ }^{7-9}$ chemical-/biosensors ${ }^{10-15}$ or optical coatings. $^{16-19}$ Meanwhile, a plethora of different synthetic routes exist, including the random dense-packing of nanoparticles, ${ }^{18,20}$ use of block copolymer (BCP) self-assembly with partial removal and optional backfilling ${ }^{21-23}$ and the coassembly from combined solutions of inorganic precursors with organic structure-directing agents such as small molecule surfactants, ${ }^{24}$ BCPs, ${ }^{25-28}$ or colloids. ${ }^{29}$

Methods for probing porosity, surface area, and pore dimensions of bulk mesoporous materials are well established and have been reported as early as the beginning of the 20th century. ${ }^{30,31}$ However, techniques such as $\mathrm{N}_{2}$ and $\mathrm{Ar}$ physisorption or mercury intrusion face natural limitations in relation to thin films due to the minimal amount of total surface area and pore volume compared to bulk measurements. Additionally, the mass of the substrate on which the film is coated typically exceeds the mass of the film itself by orders of magnitude, meaning that weight-based methods are challenged in their sensitivity toward the volume of interest. Some modifications to classical physisorption provide pathways to improved sensitivity. Krypton and toluene have been identified as suitable sorbents for thin film materials due to their lower saturation pressure compared to $\mathrm{N}_{2}$ and $\mathrm{Ar}^{32-34}$ Additionally, the coupling of surface acoustic wave (SAW) techniques to classical physisorption offers improved sensitivity, ${ }^{35-37}$ but the required low temperatures, extensive sample pretreatment, and complex isotherm interpretation limit their application.

Traditional methods of examining nanoscale surface morphologies, such as atomic force microscopy (AFM) or scanning electron microscopy (SEM), are widely employed in the characterization of thin-film mesoporous materials. ${ }^{38-42}$ Image analysis of top-view and cross-sectional micrographs can provide quantitative information about the open pores present on the sample. Yet, the accessible sample volume is restricted to the surface and the cleaved cross-section, raising questions of validity for the entire film. Other nonintrusive methods, such as small-angle neutron scattering (SANS) or small-angle X-ray scattering (SAXS) offer access to probe the $3 \mathrm{D}$ pore architecture of mesoporous bulk material. ${ }^{43-45}$ However, for thin films, standard X-ray scattering techniques suffer from the minimal volume of material and the high background scattering of the substrate. Grazing-incidence small angle scattering (GISAXS) was introduced in the late 1980 s to resolve these issues. ${ }^{46}$ GISAXS is particularly powerful at resolving structural order and the spatial pore arrangement, including anisotropy. ${ }^{47,48}$

Special Issue: Young Investigator Forum

Received: October 2, 2019

Accepted: December 16, 2019

Published: January 21, 2020 
However, complementary techniques are required (e.g., SEM or $\mathrm{X}$-ray reflection) to calculate pore size distributions, and evaluating the accessibility of pores and surface area provides further challenges. ${ }^{49,50}$

Alternatively, less widely used techniques include electron probe microanalysis (EPMA), which involves electron-excited $\mathrm{X}$-ray spectrometry in combination with $\mathrm{SEM}^{51}$ or X-ray fluorescence. $^{52,53}$ Another notable technique to probe open voids in films is positron annihilation spectroscopy (PAS). Positrons, when trapped within pores, change their annihilation lifetime behavior, which can then be related to pore volume ${ }^{54}$ and size ${ }^{55}$ via analysis of the intensity of positronium. Quartz crystal microbalance (QCM) represents an additional technique that provides access to pore size distribution and specific surface area via adsorption-desorption isotherms that are based on the mass uptake at different relative pressures. ${ }^{56}$ Electrochemical techniques, such as cyclic voltammetry and chronoamperometry, enable further evaluation of the accessibility, pore interconnection, and diffusion coefficient of porous films. ${ }^{57}$

Sorption-based techniques offer a number of advantages for porosimetry. X-ray porosimetry relies on a change in the critical angle $\left(\theta_{\mathrm{c}}\right)$ of X-ray reflectometry (XRR) as a consequence of capillary condensation within a mesoporous film. ${ }^{58}$ The $\theta_{c}$ value can then be related back to film density and mass uptake. ${ }^{59}$ In combination with small-angle neutron scattering (SANS), XRR can serve to investigate wall density and film porosity. ${ }^{60}$ Although in principle this technique provides a reliable route to porosimetry in thin films, it requires relatively complex data analysis and is not routinely used for mesoporous film characterization.

Over the past 20 years, ellipsometric porosimetry (EP) has emerged as sensitive and nondestructive physisorption technique that is capable of measuring structural characteristics in a optically transparent thin film geometry. ${ }^{61-64}$ It provides a real-time measurement of the ellipsometric angles $(\Delta, \Psi)$, which can be related to the refractive index (RI) and film thickness as a function of relative pressure of a sorbent vapor within a sample chamber. ${ }^{61,63}$ Changes in RI are linked to the adsorption and gradual filling of the open pores with gas phase sorbent molecules, ultimately leading to a complete uptake by capillary condensation. ${ }^{61}$ Analysis of the sample isotherm then enables to determine an overall accessible porosity, pore size distribution, surface area and mechanical properties. ${ }^{61-65}$ EP provides a number of distinct advantages in comparison to imaging or scattering techniques. Minimal sample pretreatment is required and data interpretation is relatively well established, building on the extensive knowledge of bulk physisorption techniques. ${ }^{33}$ Furthermore, EP can be performed with a variety of sorbent molecules depending on the nature of the material being probed. ${ }^{66-68}$ Meanwhile, environmental ellipsometric porosimetry (EEP) offers operation at ambient temperature and pressure using water as the sorbent molecule. ${ }^{63,67,69}$

In this work, we present a tutorial overview for some of the most capable and widely used techniques to probe the pore morphology, pore size distribution, surface area and overall porosity of thin-film mesoporous materials. Well-defined mesoporous inorganic architectures created by block copolymer coassembly serve as model samples, offering a rational variation of pore size and porosity. We characterize the various samples by AFM, SEM, GISAXS, and EEP and determine the accessible porosimetric properties. Finally, we compare outcomes and critically discuss advantages and disadvantages of each technique to provide guidelines for successful utilization and reliable interpretation.

\section{EXPERIMENTAL SECTION}

Preparation of Mesoporous Aluminosilicate Films. BCP coassembly relates to the structural organization of inorganic guest material by a structure-directing BCP host, which is subsequently removed to yield an ordered inorganic mesoporous network. ${ }^{70} \mathrm{PIB}_{39}-b$ $\mathrm{PEO}_{36} \mathrm{BCP}\left(M_{\mathrm{n}} 4.85 \mathrm{~kg} / \mathrm{mol}\right.$; polydispersity index (PDI) 1.26$)$ was supplied by BASF following a previously reported synthetic route. ${ }^{71}$ PIB homopolymer was purchased from Polymer Source $\left(M_{\mathrm{n}} 1.5 \mathrm{~kg} /\right.$ mol; PDI 1.20). The synthesis of the sol, mixing with the block copolymer and fabrication of the mesoporous inorganic aluminosilicate films was carried out as previously described. ${ }^{72,73}$ Notably, the porosity was tuned via the mixing ratio between inorganic sol and sacrificial BCP in the initial solution. ${ }^{17,39}$ The pore size was modified by using PIB homopolymer as a swelling agent of the porous structure. ${ }^{74}$ In short, $\mathrm{BCP}$ and homopolymer were first dissolved in a toluene/1-butanol azeotrope solution and stirred for $1 \mathrm{~h}$. Then, the sol was added dropwise before the solution was agitated for another hour. The exact combination of solvent, BCP, homopolymer and sol for each sample is shown in Table 1. All samples were spin-coated at $2000 \mathrm{rpm}$ for $20 \mathrm{~s}$

Table 1. List of Samples That Served for Porosimetric Characterization during This Work

\begin{tabular}{lcccc} 
sample & $\begin{array}{c}\text { mass of } \\
\mathrm{BCP}(\mathrm{mg})\end{array}$ & $\begin{array}{c}\text { mass of } \\
\text { sol }(\mathrm{mg})\end{array}$ & $\begin{array}{c}\text { mass of } \\
\mathrm{HP}(\mathrm{mg})\end{array}$ & $\begin{array}{c}\text { volume of toluene/1- } \\
\text { butanol azeotrope }(\mathrm{mL})\end{array}$ \\
$\mathrm{A}_{10}$ & 5 & 90 & - & 0.337 \\
$\mathrm{~A}_{20}$ & 5 & 40 & - & 0.238 \\
$\mathrm{~A}_{20+\mathrm{HP}}$ & 5 & 40 & 1.9 & 0.238 \\
\hline
\end{tabular}

and immediately annealed on a programmable hot plate using a ramp rate of $1{ }^{\circ} \mathrm{C}$ per min to a final temperature of $130^{\circ} \mathrm{C}$ for $30 \mathrm{~min}$. To remove the $\mathrm{BCP}$, samples were calcined in a muffle furnace at $450{ }^{\circ} \mathrm{C}$ for $1 \mathrm{~h}$. The nomenclature $\mathrm{A}_{x}$ indicates the organic-inorganic ratio in the initial solution, for example, $A_{10}$ refers to a sample with $10 \%$ organic content. 20+HP denotes the further addition of a homopolymer swelling agent.

Samples Characterization. AFM images were obtained on a Bruker Dimension Icon atomic force microscope with a Bruker ScanAsyst Air probe (nominal tip radius $2 \mathrm{~nm}$ ) in PeakForce tapping (PFT) mode. The average pore radius was determined by analysis of the real space topography images using the software Pebbles. ${ }^{75}$

SEM was carried out on a field emission ZEISS CrossBeam 540 equipped with a Gemini 2 electron column. Secondary electron images on pristine samples were acquired at an acceleration voltage of $2 \mathrm{kV}$ using an in-lens detector. Image analysis of the scanning electron micrographs was conducted in analogy to AFM.

GISAXS experiments were performed on a SAXSLab Ganesha (8 $\mathrm{keV}$ ). The incidence angle was set at $0.2^{\circ} .2 \mathrm{D}$ scattering patterns were collected with a PILATUS $300 \mathrm{~K}$ solid-state photon-counting detector at a sample-to-detector distance of $950 \mathrm{~mm}$. GISAXS data analysis was accomplished with the FitGISAXS ${ }^{76}$ software.

Ellipsometric porosimetry (EP) measurements were carried out on a Semilab SE2000 variable angle spectroscopic ellipsometer in the spectral range of 300 to $1000 \mathrm{~nm}$. All data analysis was performed using the Semilabs SEA software (v1.6.2). Prior to EP measurements, samples were placed on a hot plate at $120{ }^{\circ} \mathrm{C}$ for $10 \mathrm{~min}$ to remove residual atmospheric water molecules inside the pores.

\section{RESULTS AND DISCUSSION}

As outlined above, a full porosimetric characterization of the three model samples was carried out by AFM, SEM, GISAXS, and EP. In the following, results will be separately shown for each technique, followed by a comparative discussion and provision of guidelines. 

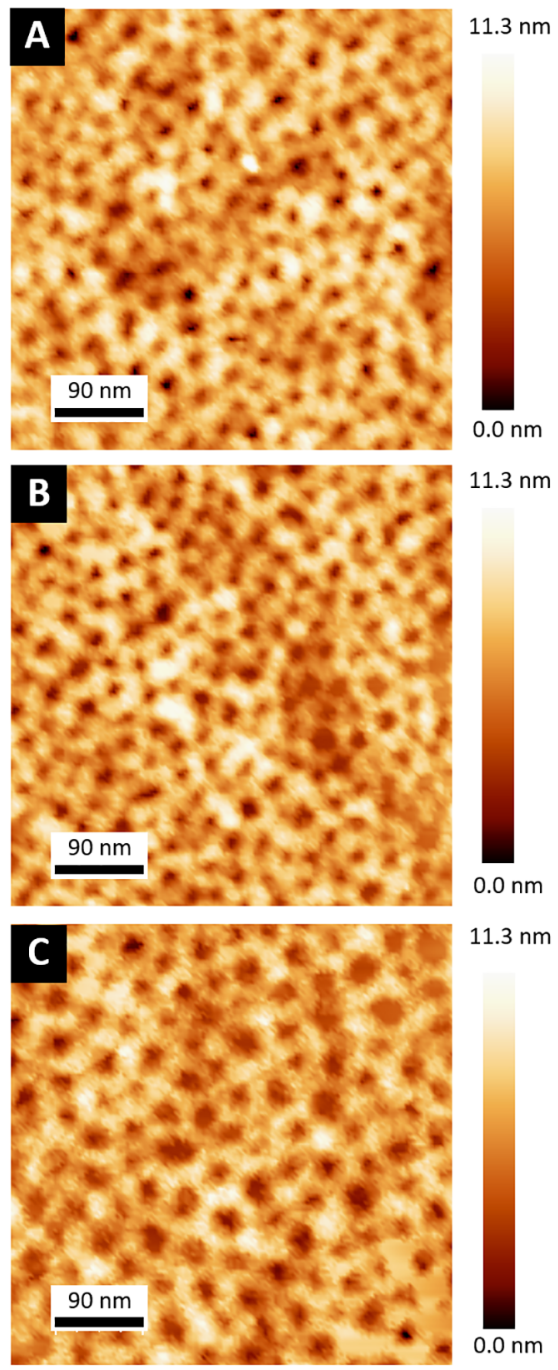
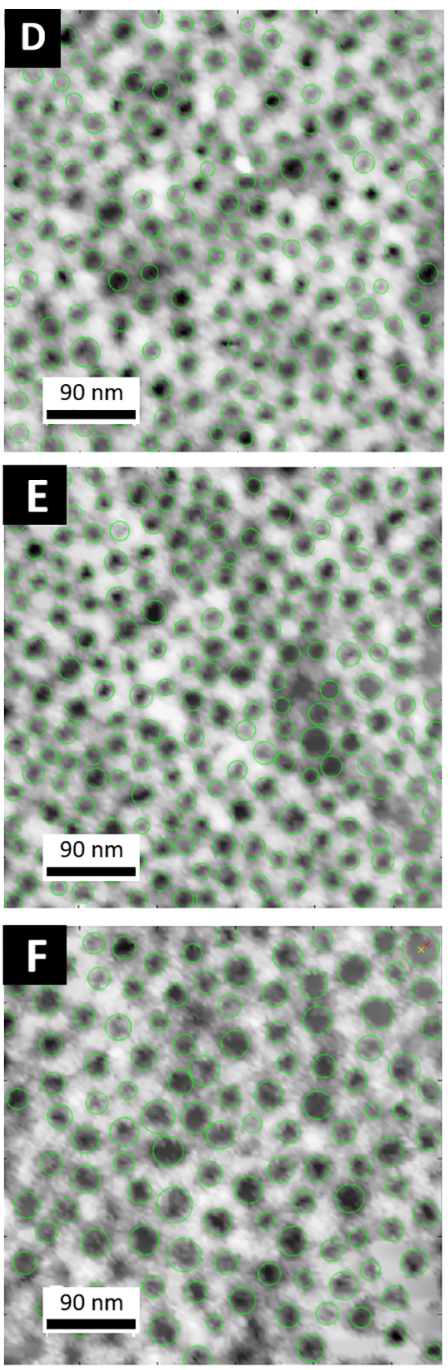
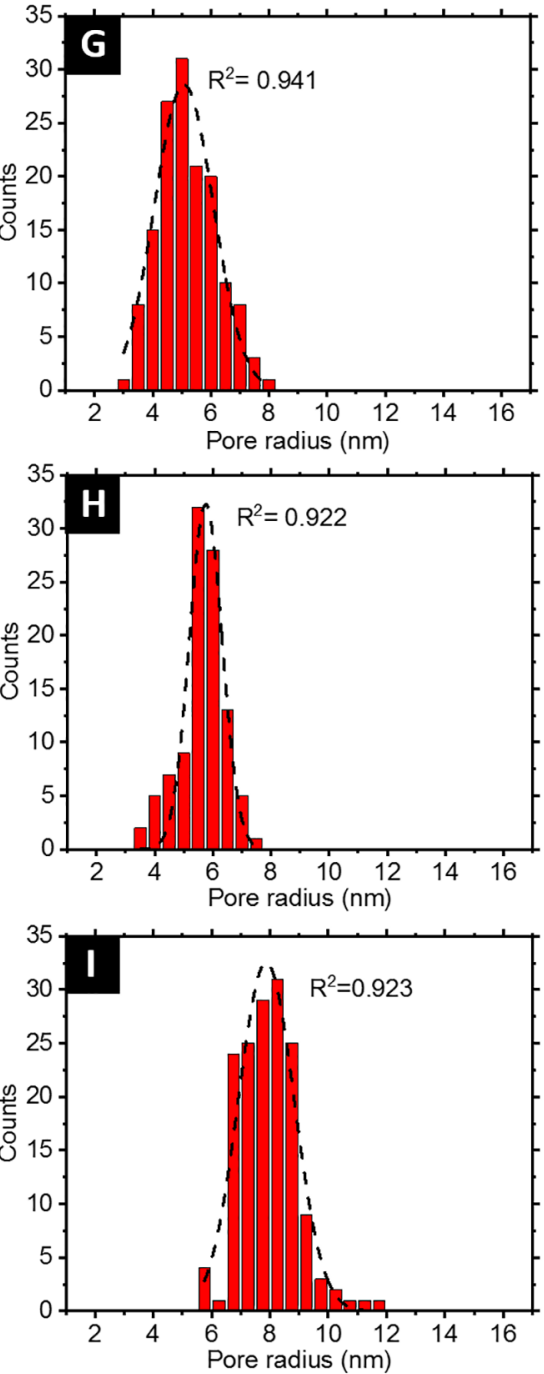

Figure 1. AFM-based surface pore analysis: AFM topographical images of the mesoporous aluminosilicate films (A) $A_{10},(B) A_{20}$, and (C) $A_{20+H P}$. $(D-$ F) Image overlay with pore recognition and $(\mathrm{G}-\mathrm{I})$ pore radius histograms obtained by the image analysis software Pebbles. ${ }^{75}$

Atomic Force Microscopy. Figure $1 \mathrm{~A}-\mathrm{C}$ shows the topographical AFM micrographs of the mesoporous aluminosilicate films. PFT mode allows to obtain high resolution images since the cantilever is oscillating below its resonant frequency in intermittent contact with the sample surface. Herein, we were able to combine beneficial aspects of both contact and tapping mode imaging, i.e., good force control and avoidance of damaging lateral forces. In all cases, the images show the presence of an ordered porous network. To gain more quantitative insights of the porous structures, the power spectral density (PSD) function was calculated for each sample (Figure S1A). A correlation peak is clearly discernible for each sample, which enables the extraction of a mean interpore distance at $k=$ $2 \pi / \lambda$ (Table 2). For our model samples, we observed a slight increase in the center-to-center pore distance when decreasing the organic:inorganic ratio of the $\mathrm{BCP}$, from $D_{c-c}\left(\mathrm{~A}_{20}\right)=23.2 \pm$ $3.2 \mathrm{~nm}$ to $D_{c-c}\left(\mathrm{~A}_{10}\right)=26.8 \pm 2.5 \mathrm{~nm}$, which is in agreement with previous observations. ${ }^{28}$ The presence of a swelling agent led to an enlargement of the center-to-center pore distance $\left(D_{c-c}\left(A_{20+H P}\right)=31.3 \pm 2.7 \mathrm{~nm}\right)$.

Another important parameter in the structural characterization of mesoporous architectures is the pore size. Various software packages, such as Image,$^{77}$ Pebbles, ${ }^{75}$ and Visio
Table 2. Accessible Structural Parameters by Image Analysis of the AFM Micrographs

\begin{tabular}{lccccc} 
sample & $\begin{array}{c}\text { in-plane } D_{\mathrm{cc}} \\
(\mathrm{nm})\end{array}$ & $\begin{array}{c}\text { out-of- } \\
\text { plane } D_{\mathrm{ccc}}\end{array}$ & $\begin{array}{c}\text { in-plane } D_{\mathrm{p}} \\
(\mathrm{nm})\end{array}$ & $\begin{array}{c}\text { out-of-plane } \\
D_{\mathrm{p}}(\mathrm{nm})\end{array}$ & $\begin{array}{c}\text { porosity } \\
(\%)\end{array}$ \\
$\mathrm{A}_{10}$ & $26.8 \pm 3.2$ & n.a. & $11.6 \pm 3.4$ & n.a. & n.a. \\
$\mathrm{A}_{20}$ & $23.2 \pm 2.5$ & n.a. & $11.3 \pm 4.3$ & n.a. & n.a. \\
$\mathrm{A}_{20+\mathrm{HP}}$ & $31.3 \pm 2.7$ & n.a. & $15.1 \pm 4.1$ & n.a. & n.a. \\
\hline
\end{tabular}

Assistant, ${ }^{78}$ have been developed to facilitate quantitative image analysis. Many of these tools are based on image segmentation via thresholding or edge detection. Alternatively, some software packages perform direct feature extraction via a series of Hough transforms. Common challenges faced by these routines include poor accuracy and user bias due to low micrograph resolution, poor signal-to-noise, inhomogeneous background, and limited convergence testing for the filter parameters. Micrograph resolution can be improved by the usage of special AFM probes i.e. single carbon nanotube ${ }^{79}$ or diamond tips, ${ }^{80}$ offering pathways to a more accurate analysis. Pebbles, a popular tool for the analysis of TEM images, takes a distinct approach as it models the transmission of electrons through 3D nano-objects and approximates their position and size via fitting of $2 \mathrm{D}$ signal 

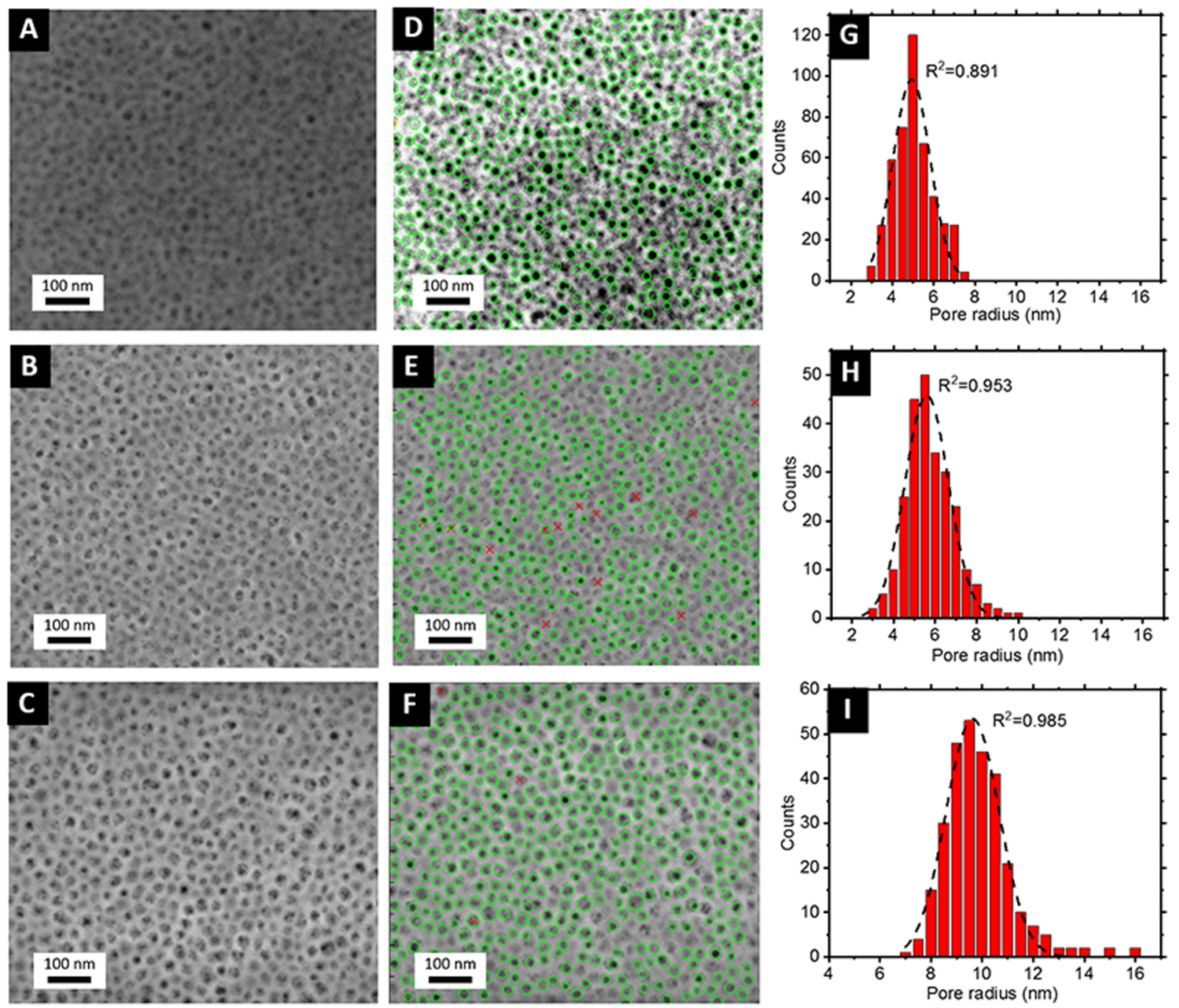

Figure 2. SEM-based suface pore analysis: SEM images of the calcined mesoporous aluminosilicate films (A) $A_{10},(B) A_{20}$, and (C) $A_{20+H P} \cdot(D-F)$ Image overlay with pore recognition by the image analysis software Pebbles. ${ }^{75}$ (G-I) Pore radius distribution histograms obtained by SEM image analysis fitted with Gaussian distributions.

intensity models. Notably, we found this method to also recognize mesopores reliably, with similar results to ImageJ (v1.52a) but following a more automated routine with less user interference.

Pore size distribution histograms show that the mean in-plane pore size remained constant with the change in the organicinorganic ratio in the initial solution, i.e., $11.6 \pm 3.4 \mathrm{~nm}$ for $\mathrm{A}_{10}$ and $11.3 \pm 4.3 \mathrm{~nm}$ for $A_{20}$, increasing with the addition of the swelling agent to $15.1 \pm 4.1 \mathrm{~nm}$ for $A_{20+H P}$. Table 2 lists all the morphological parameters of the mesoporous thin films obtained by AFM. As previously discussed, sample analysis by AFM is restricted to the surface topology and thus neither outof-plane pore dimensions and spacing nor porosity could be determined.

Scanning Electron Microscopy (SEM). The mesoporous films were also characterized by scanning electron microscopy (SEM). The micrographs of the films imaged in top view (Figure 2A-C) show comparable information to AFM. The contrast in the images is entirely topographic and the use of an in-lens detector (directly on axis with the electron beam) limits the introduction of asymmetric features. Most notably, the depth of imaging is different for the two techniques. Although AFM is sensitive only to the top layer of the porous film, the secondary electrons collected in SEM may originate from deeper inside the film. This can result in an apparent higher density of features in the SEM images compared to the AFM topology, evidenced in Figure $2 \mathrm{~A}-\mathrm{C}$ with a wider distribution of contrast levels. Quantification of the surface pore structure was carried out via the same workflow in Pebbles (Figure 2D-F). Table 3 lists all the relevant morphological parameters obtained by SEM characterization. In-plane pore dimensions were measured at $11.0 \pm 3.1,11.5 \pm 2.9$, and $18.2 \pm 2.7 \mathrm{~nm}$ for $\mathrm{A}_{10}, \mathrm{~A}_{20}$, and $A_{20+H P}$, respectively. The corresponding in-plane pore spacing, obtained by FFT of the SEM images, were $26.2 \pm 2.7 \mathrm{~nm}\left(\mathrm{~A}_{10}\right)$,

Table 3. Accessible Structural Parameters by Image Analysis of the SEM Micrographs

$\begin{array}{lccccc}\text { sample } & \begin{array}{c}\text { in-plane } D_{\text {cc }} \\ (\mathrm{nm})\end{array} & \begin{array}{c}\text { out-of- } \\ \text { plane } D_{\text {c-c }} \\ (\mathrm{nm})\end{array} & \begin{array}{c}\text { in-plane } D_{\mathrm{p}} \\ (\mathrm{nm})\end{array} & \begin{array}{c}\text { out-of- } \\ \text { plane } D_{\mathrm{p}} \\ (\mathrm{nm})\end{array} & \begin{array}{c}\text { porosity } \\ (\%)\end{array} \\ \mathrm{A}_{10} & 26.2 \pm 2.7 & \text { n.a. } & 11.0 \pm 3.1 & \text { n.a. } & \text { n.a. } \\ \mathrm{A}_{20} & 23.5 \pm 3.1 & \text { n.a. } & 11.5 \pm 2.9 & \text { n.a. } & \text { n.a. } \\ \mathrm{A}_{20+\mathrm{HP}} & 32.0 \pm 2.5 & \text { n.a. } & 18.2 \pm 2.7 & \text { n.a. } & \text { n.a. }\end{array}$



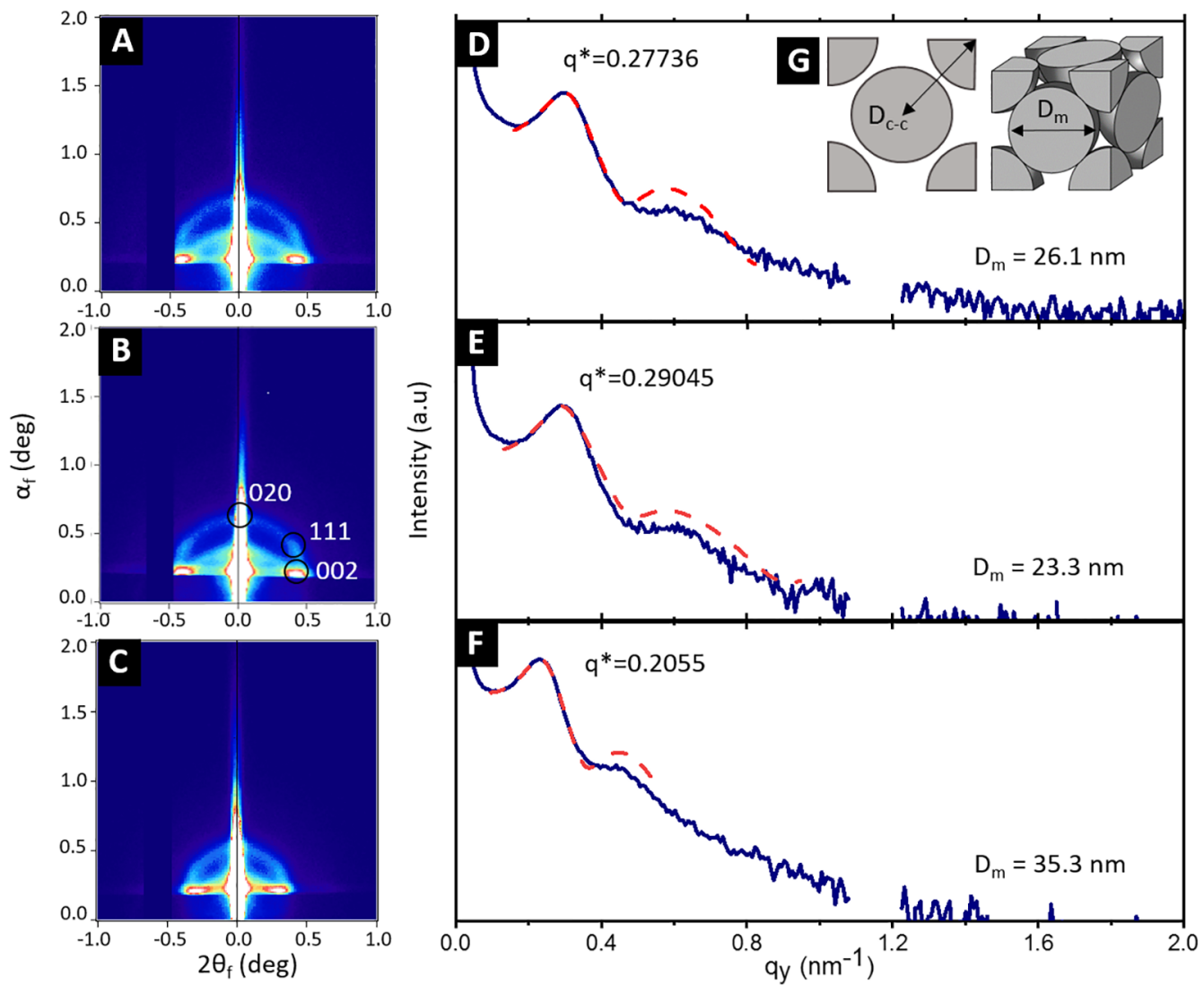

Figure 3. (A-C) 2D GISAXS scattering patterns and (D-F) in-plane GISAXS line cuts along $q_{y}$ for the hybrid films before calcination: (A, D) $A_{10}$, (B, E) $A_{20}$, and $(C, F) A_{20+H P}$. The dashed lines represent fitting patterns for spherical objects with a diameter $D_{m}$, arranged in a $2 D$ hexagonal paracrystalline array. $(\mathrm{G})$ Schematic of the proposed morphology.

$23.5 \pm 3.1 \mathrm{~nm}\left(\mathrm{~A}_{20}\right)$, and $32.0 \pm 2.5 \mathrm{~nm}\left(\mathrm{~A}_{20+\mathrm{HP}}\right)$, respectively. Cross-sectional SEM from cleaved Si wafers enabled to gather more information on the $3 \mathrm{D}$ porous structure (Figure S2). Ellipsoidal pores were observed, likely arising from the contraction of the film during the calcination process. Nevertheless, difficulties in obtaining high-resolution images of sufficiently large cross-sectional areas limit the out-of-plane information to qualitative evidence.

Grazing Incidence Small-Angle X-ray Scattering. The GISAXS experimental setup utilizes an X-ray beam directed to the sample at small incident angles, typically on the order of 0.05 to $1^{\circ}$, in-between the critical angle of the substrate and material film of study, in order to probe the structural features of the thin film with a sufficiently long path length (see Figure S3). A beam stop hides the direct beam and the $2 \mathrm{D}$ detector records the intensity of the two reflection angles $\alpha_{\mathrm{f}}$ and $2 \theta$, which correspond to the out-of-plane and in-plane scattering. The inplane scattering intensity provides information on the repeating unit structure parallel to the surface of the substrate, while the out-of-plane scattering supplies information about the normalto-film surface direction. ${ }^{47,48,81-83}$ Scattering angles are reported as the scattering vector, $q$, which incorporates the wavelength of the X-ray source $\lambda$ (see eq 1 ).

$$
q=\frac{4 \pi}{\lambda} \sin \theta
$$

In this work, GISAXS experiments were performed on the mesoporous films before and after calcination, using an incidence angle of $0.2^{\circ}$. GISAXS data analysis was carried out with the FitGISAXS software. ${ }^{76}$ Figure $3 \mathrm{~A}-\mathrm{C}$ presents the $2 \mathrm{D}$
GISAXS scattering patterns for the hybrid samples before calcination. In all the cases, Bragg diffraction spots can be clearly observed, confirming the high degree of spatial organization of the micelles. The presence of poly oriented domains are further confirmed by diffraction ring present in all the images. The GISAXS pattern line-cuts along $q_{y}$ integrated around the Yoneda band are shown in Figure 3D-F. In-plane pore center-to-center distances $\left(D_{\mathrm{c}-\mathrm{c}}\right)$ were calculated with respect to the position of the first Bragg peak $\left(q^{*}\right)$, showing an enlargement of the porous structure with the presence of the swelling agent. To obtain further structural information, the scattering patterns can be fitted to different model arrangements using software packages such as FitGISAXS, ${ }^{76}$ HipGISAXS ${ }^{84}$ or IsGISAXS. ${ }^{85}$ In our case, the samples were in best agreement to a $2 \mathrm{D}$ hexagonal paracrystalline array of spherical objects (see dotted lines in Figure $3 \mathrm{D}-\mathrm{F}$ ) using FitGISAXS ${ }^{76}$ This is consistent with earlier studies, where similar patterns were identified as a face-centerd cubic (FCC) structure with (010) planes parallel to the substrate. ${ }^{86}$ A schematic of the proposed morphology is shown in Figure 3G.

Figure 4 presents the 2D GISAXS scattering pattern for the calcined samples. A remarkable elongation of the Bragg spots in the $q_{z}$ direction is clearly visible. See the Figure $S 4$ for a full evaluation of the film compression and shrinkage via comparison of the 2D GISAXS scattering patterns before and after calcination. The porosity of the mesoporous structures can be quantitatively determined from the vertical cuts of the GISAXS patterns ${ }^{87,88}$ by extracting the critical angles (the angle below the beam is fully reflected from the film) in reciprocal-space $\left(q_{\mathrm{c}}\right)$ from the Yoneda peaks (Figure 4D-F). The complex index of 

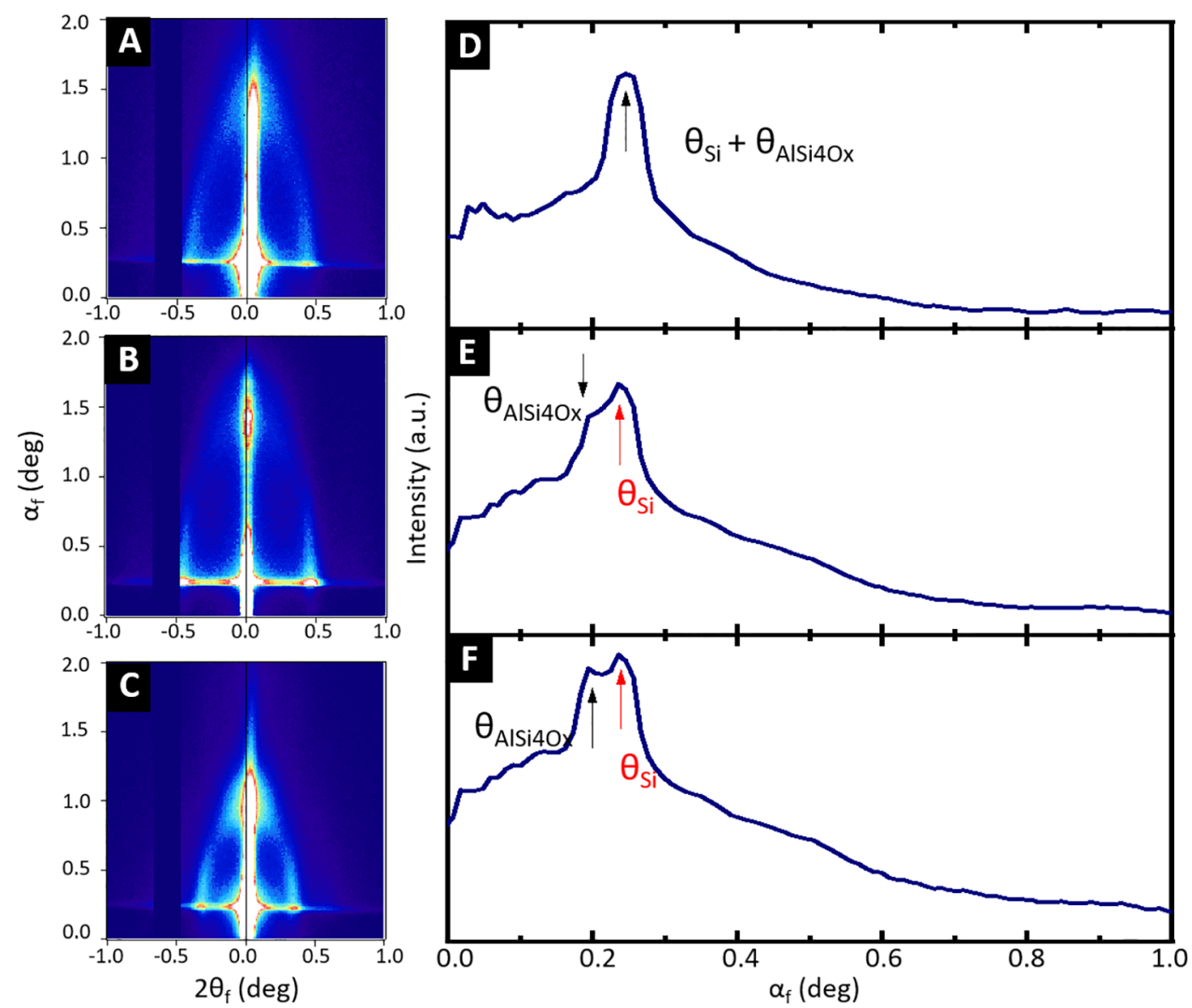

Figure 4. (A-C) 2D GISAXS scattering patterns and (D-F) out-of plane GISAXS line cuts along $\alpha_{\mathrm{f}}$ for the calcined mesoporous aluminosilicate films: $(A, D) A_{10}$; $(B, E) A_{20}$, and $(C, F) A_{20+H P}$. The arrows indicate the identified critical angles.

refraction in the X-ray region may be written as $n=1-\delta-i \beta$. The absorption contribution $\beta$ is usually negligible, and thus scattering mainly depends on the dispersion $\delta$, which is associated with the electron density of the material. ${ }^{89}$ The dispersion $\delta$ may also be expressed as scattering length density (SLD), which is related to $q_{\mathrm{c}}$ as follows:

$$
q_{\mathrm{c}}=\sqrt{16 \pi \mathrm{SLD}}
$$

A theoretical $\mathrm{SLD}_{\mathrm{AlSi} 4 \mathrm{Ox}}$ value of $2.15 \times 10^{-5} \AA^{-2}$ was calculated for the amorphous aluminosilicate material with 4:1 molar ratio of Si:Al and a density of $2.52 \mathrm{~g} / \mathrm{cm}^{-3}$, based on an earlier study that found the aluminum in equal parts in tetrahedral or octahedral coordination, i.e. evenly distributed in the silicaframework and in segregated aluminum microdomains. ${ }^{90}$ This value is very similar to the SLD value corresponding to the silicon substrate $\left(\mathrm{SLD}_{\mathrm{Si}}=2.0 \times 10^{-5} \AA^{-2}\right)$.

As indicated in Figure $4 \mathrm{E}-\mathrm{F}$ two distinct critical angles were observed for both $\mathrm{A}_{20}$ and $\mathrm{A}_{20+\mathrm{HP}}$ at 0.181 and $0.224^{\circ}$, respectively, corresponding to values of $\mathrm{SLD}_{1}=1.30 \times 10^{-5}$ $\AA^{-2}$ and $S_{L D}=2.0 \times 10^{-5} \AA^{-2}$. A porosity of $\sim 40 \%$ then follows by comparison of the mesoporous structure SLD $\left(\mathrm{SLD}_{1}\right)$ and the theoretical SLD of the nonporous aluminosilicate material $\left(\mathrm{SLD}_{\mathrm{AlSi} 4 \mathrm{Ox}}\right) .{ }^{88}$ Note that we only observed one critical angle for $\mathrm{A}_{10}$ at $0.232^{\circ}$, corresponding to a SLD of $2.1 \times 10^{-5} \AA^{-2}$, which did not allow an evaluation of porosity due to the overlap with the SLD value of the Si substrate. Alternative indirect methods to probe the porosity by GISAXS require the input of complementary techniques, e.g., SEM or XRR. ${ }^{50,91}$ A porosity value of the thin film may then be calculated based on geometric models, by taking into account the $3 \mathrm{D}$ arrangement of the mesoporous structure established by GISAXS and the pore size distribution obtained by AFM and SEM. ${ }^{50}$ Table 4 summarizes all relevant morphological parameters of the mesoporous thin films obtained by GISAXS characterization.

Table 4. Accessible Structural Parameters by Analysis of the GISAXS Scattering Patterns for the Calcined Samples

\begin{tabular}{lccccc} 
sample & $\begin{array}{c}\text { in-plane } \\
D_{\text {c-c }}(\mathrm{nm})\end{array}$ & $\begin{array}{c}\text { out-of-plane } \\
D_{\text {c-c }}(\mathrm{nm})\end{array}$ & $\begin{array}{c}\text { in-plane } \\
D_{\mathrm{p}}(\mathrm{nm})\end{array}$ & $\begin{array}{c}\text { out-of-plane } \\
D_{\mathrm{p}}(\mathrm{nm})\end{array}$ & $\begin{array}{c}\text { porosity } \\
(\%)\end{array}$ \\
$\mathrm{A}_{10}$ & 28.2 & 11.3 & n.a. & n.a. & n.a. \\
$\mathrm{A}_{20}$ & 26.8 & 10.1 & n.a. & n.a. & 40 \\
$\mathrm{~A}_{20+\mathrm{HP}}$ & 36.7 & 15.3 & n.a. & n.a. & 40 \\
\hline
\end{tabular}

Ellipsometric Porosimetry (EP). Ellipsometry is a technique that relates changes in the polarization of optical light to the dielectric properties of a thin film. The calcined mesoporous aluminosilicate films were characterized for their refractive index (RI) and film thickness under variable relative water pressure. To calculate the material porosity from the RI adsorption isotherm, an effective medium approximation (EMA) is required, which relates the measured increase of the $\mathrm{RI}$ value to the volume adsorbed. The most common approach is based on the Lorentz-Lorentz EMA model, which utilizes the polarizability and molar volume of the sorbent (see eq 3 ). 

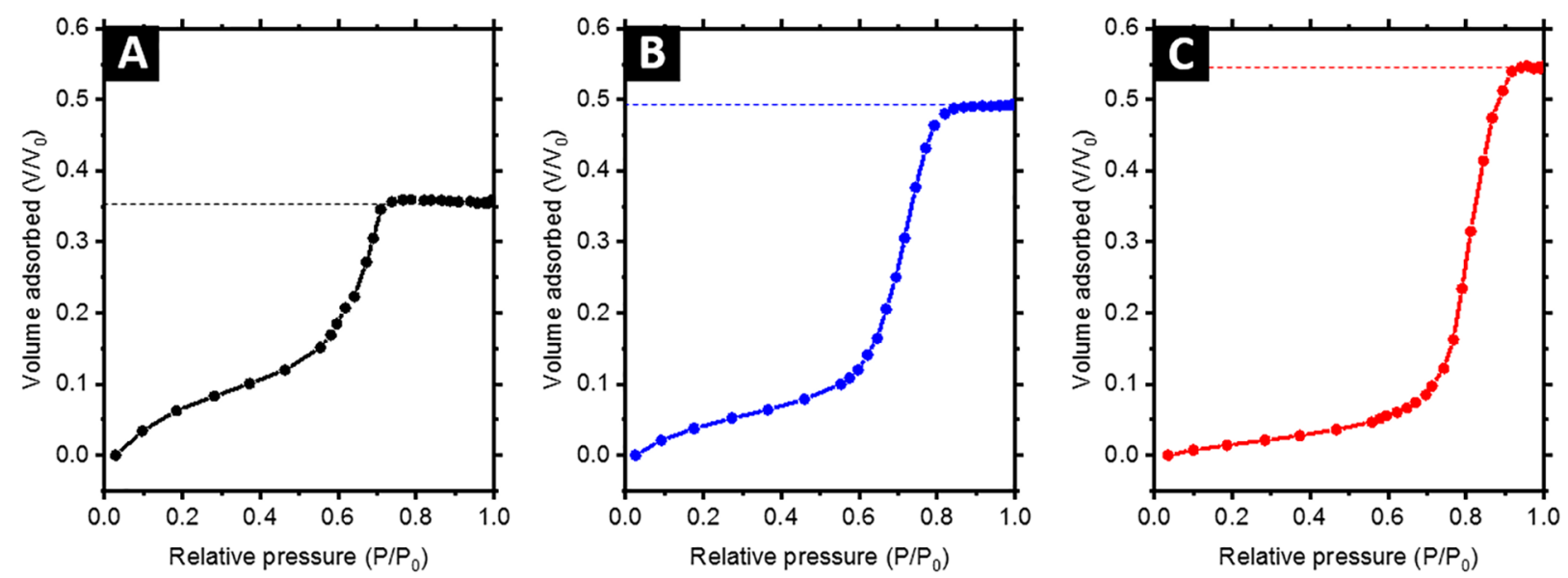

Figure 5. EP adsorption isotherms for the three samples studied: (A) $A_{10}$, (B) $A_{20}$, and (C) $A_{20+H P}$.
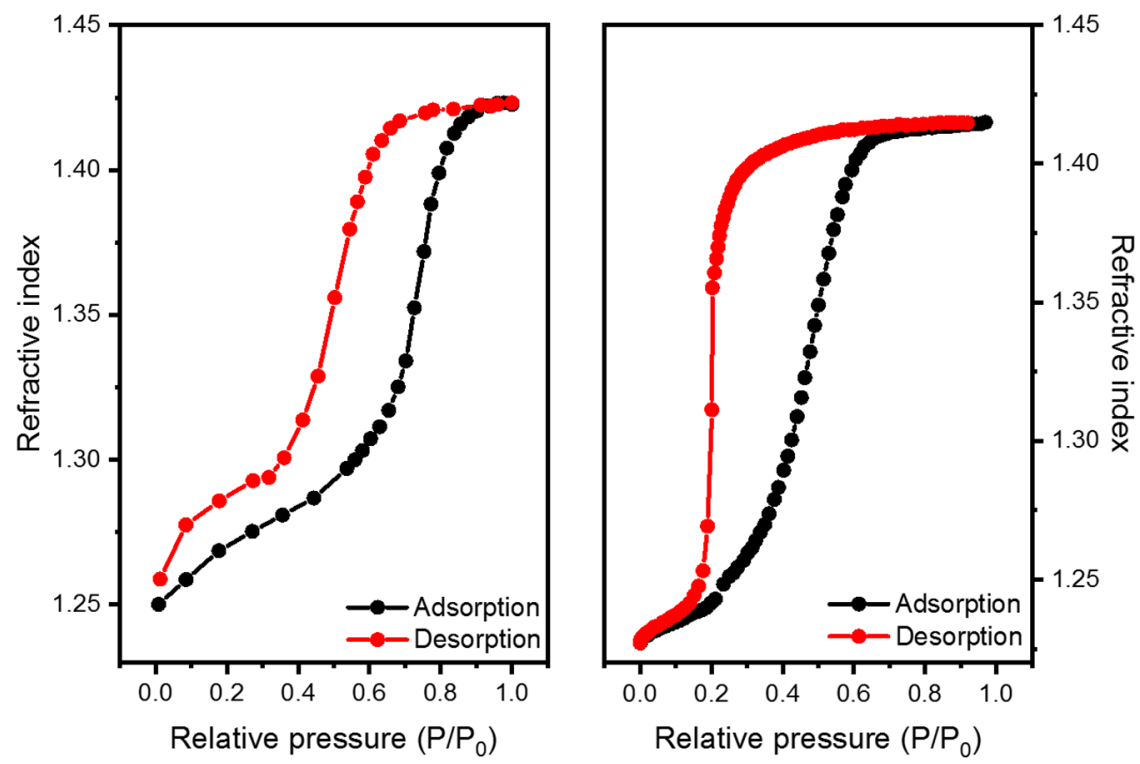

Figure 6. EP measurements of $A_{20}$ using (A) water and (B) toluene as sorbent. Inset: schematic of the ink-bottle pore type.

$$
V=1-\frac{B_{\mathrm{a}}}{B_{\mathrm{b}}}=\left[\frac{\left(\frac{n_{\mathrm{a}}^{2}-1}{n_{\mathrm{a}}^{2}+2}\right)}{\left(\frac{n_{\mathrm{b}}^{2}-1}{n_{\mathrm{b}}^{2}+2}\right)}\right]
$$

Where $V$ is the volume of water adsorbed into the pores, $B_{\mathrm{a}}$ and $n_{\mathrm{a}}$ are the volume polarizability and refractive index of the skeleton material, and $B_{\mathrm{b}}$ and $n_{\mathrm{b}}$ are the volume polarizability and refractive index calculated in the pores at each measurement point. Figure 5 shows the EP adsorption isotherms obtained for the respective samples. A significant rise in the porosity was observed with an increase in the organic-inorganic ratio from 35 to $50 \%\left(\mathrm{~A}_{10}\right.$ vs $\left.\mathrm{A}_{20}\right)$, whereas only a small further enhancement to $54 \%$ was found with the presence of the swelling agent $\left(\mathrm{A}_{20+\mathrm{HP}}\right)$.

The Lorentz-Lorentz EMA provides the benefit of not requiring the refractive index of the wall or skeleton material that surrounds the pores. However, concerns have been raised on whether the properties of the condensed adsorbate were identical to the bulk liquid. ${ }^{92-94}$ Boissiere et al. proposed the use of the Bruggeman EMA as an alternative approach. ${ }^{92}$ As shown in the Figure S5, we found minimal differences between both effective medium approximation calculations, indicating that both EMA approaches provide consistent results for the presented sample types.

The shape of the EP refractive index adsorption and desorption isotherms can provide important information on the structural configuration of the porous material. In Figure 6 the hysteresis loop is shown for sample $A_{20}$ when measured using water and toluene as sorbent, respectively.

In both cases, type IV isotherms were observed, as categorized by IUPAC. ${ }^{33}$ However, a clear difference in the hysteresis loops can be identified depending on the sorbent. For water-based EP, the hysteresis could be attributed to either type $\mathrm{H} 1$ or $\mathrm{H} 2 \mathrm{~b} .{ }^{33} \mathrm{In}$ H1-type isotherms, the origin of hysteresis is related to the difference in the shape of the meniscus for a cylindrical pore during the adsorption and desorption cycle, i.e., a semi-infinite cylindrical meniscus during condensation and a hemispherical meniscus during evaporation. ${ }^{95,96}$ A H2b-type hysteresis loop indicates pores that are interconnected by narrow restrictions ("ink-bottle"-type connections), which delay evaporation until a certain vapor pressure to induce a simultaneous emptying of the narrow restrictions and pores. ${ }^{33,95}$ In the present case, differentiating between cylindrical $(\mathrm{H} 1)$ and ink-bottle ( $\mathrm{H} 2 \mathrm{~b})$ 

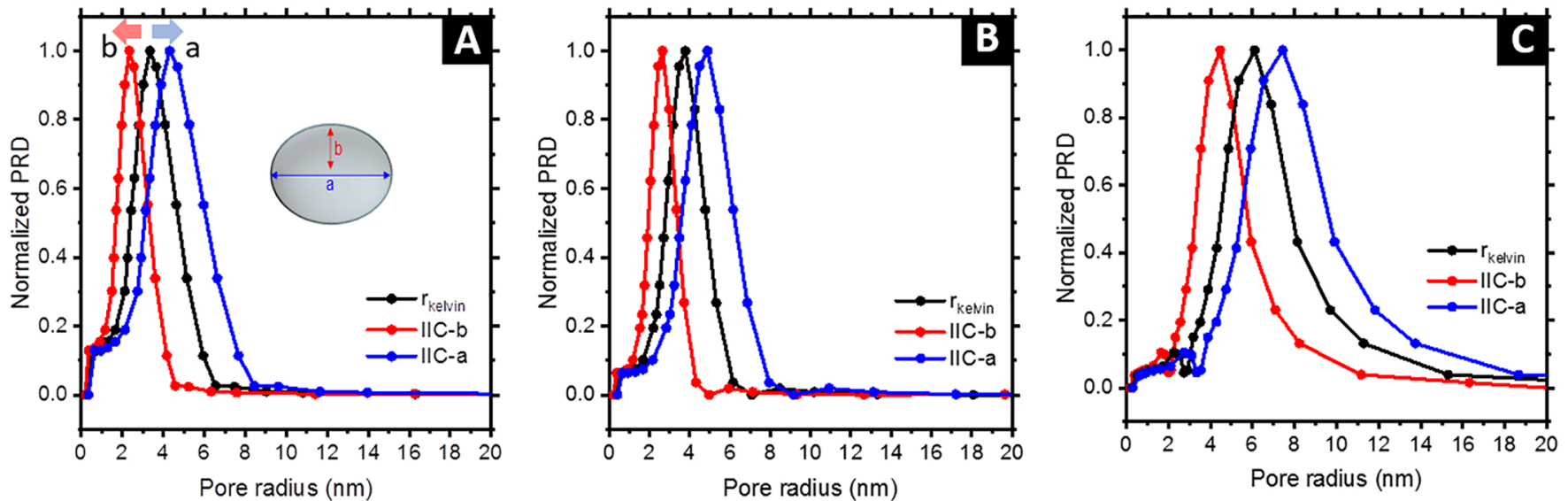

Figure 7. Pore size distribution obtained by EP for the different samples studied: (A) $A_{10},(B) A_{20}$, and $(C) A_{20+H P}$ following application of the modified Kelvin equation (black curve) and IIC model adjustments to yield (a) large ellipsoidal (blue curves) and (b) small ellipsoidal (red curves) pore dimensions.

pores would be difficult for water-based EP alone. However, the toluene isotherm is clearly of hysteresis type $\mathrm{H} 2 \mathrm{a}$, thus attributed to either emptying of pore necks with a narrow size distribution or evaporation of the liquid via cavitation-induced evaporation (see Figure S6). Cavitation takes place when gas bubbles nucleate within liquid condensate at certain vapor pressures, inducing spontaneous evaporation of the liquid. ${ }^{33}$ On the basis of these observations, it is unlikely that the pores are cylindrical in shape. The nature of the toluene EP hysteresis is consistent with cavitation taking place at a relative pressure of 0.2 , which is in line with previous studies. ${ }^{97}$ This indicates the presence of ink-bottle type restrictions between pores. ${ }^{95}$ Because of these cavitation effects, pore neck size cannot be reported in the present case using the toluene-based EP desorption data.

Pore Size Determination. EP analysis allows for determination of a pore radius distribution from the adsorption isotherm. This is calculated from a modified Kelvin equation (see eq 4).

$$
r_{\mathrm{k}}=\frac{2 \gamma V_{1} \cos \theta}{R T \ln (R H)}
$$

Where $r_{\mathrm{k}}$ is the Kelvin radius; $\gamma$ and $V_{\mathrm{L}}$ are the water surface tension and molar volume, respectively; and $\mathrm{RH}$ is the relative humidity. The pore radius, $r_{\mathrm{T}}$, is equal to the Kelvin radius plus a thickness equivalent to the initial layer of water adsorbed to the pore. A pore size distribution (PSD) is subsequently calculated from the derivative of the cumulative volume adsorbed based on the methods initially proposed by Barrett, Joyner, and Halenda (BJH). ${ }^{98}$

Some modifications to the Kelvin equation are required to obtain an accurate pore size determination from EP adsorption measurements. In a first step, it is important to remark that prior to capillary condensation, multiple layers of vapor molecules adsorb to the surface of the pore. Consequently, the $r_{\mathrm{k}}$ value measures the size of the pore after the initial layer formation of vapor molecules, therefore requiring a correction. The monolayer thickness, $t$, is typically estimated on the basis of adsorption of sorbent vapor molecules on chemically similar nonporous samples, following the BET equation. ${ }^{95,99}$

A further adjustment to the Kelvin radius relates to the contact angle of the liquid sorbent molecules and the pore surface. ${ }^{92,99}$ Generally, because of the complexity of a direct measurement, the microscopic contact angle is assumed to be equal to zero. ${ }^{99,100}$ Other researchers have advocated for the use of the macroscopic contact angle in the EP Kelvin equation ${ }^{63}$ or a correction factor to align results of various sorbents. ${ }^{95}$ As shown in Figure S7, the obtained pore size distributions using water and toluene as sorbents showed consistent results for a contact angle of $0^{\circ}$, which can also be justified by the presence of an initially adsorbed monolayer of sorbent.

Another aspect to consider is the pore anisotropy that originates from film contraction normal to the substrate during processing. To account for the resulting ellipsoidal pore shape, Boissiere et al. ${ }^{63}$ devised the isotropic inorganic pore contraction (IIC) model, where the Kelvin equation is adjusted by a geometric coefficient, $G$, which describes the anisotropic nature of the ellipsoidal pores and the influence of film shrinkage on the large (a) and small (b) ellipsoidal radii.

$$
\ln \frac{p}{p_{0}}=\frac{-\cos \theta_{\gamma} V_{\mathrm{L}}}{R T} \frac{G}{b}
$$

The geometric coefficient is derived from the anisotropy parameter, $p$, which is calculated on the basis of film shrinkage.

$$
p=\left(\frac{d_{\text {film,spun }}}{d_{\text {film,calcined }}}\right)\left(\frac{d_{\text {ref,calcined }}}{d_{\text {ref,spun }}}\right)^{1 / 3}
$$

Where $d_{\text {film }}$ and $d_{\text {ref }}$ are thickness values for the porous film and the nonporous inorganic film, respectively. Subscripts spun and calcined relate to the film thicknesses before and after thermal calcination. The small radius is multiplied by the anisotropy parameter to calculate the large radius, $a$.

In the present case, nonporous aluminosilicate contracted by an average of $\sim 62 \%$, whereas similar film thickness shrinkage of $\sim 62 \%$ led to the calculation of the anisotropy parameter at 1.93 with adjustments of 0.7 and 1.35 for the small and large radii, respectively.

Monolayer, contact angle, and pore anisotropy adjustments were incorporated into the Kelvin equation to calculate the PSD data based on the EP measurements, presented in Figure 7A-C for the three mesoporous samples $A_{10}, A_{20}$, and $A_{20+H P}$. The higher organic-inorganic ratio for $A_{20}$ in comparison to $A_{10}$ led to an only marginal variability of the in-plane $(10.9 \pm 0.7$ to 10.7 $\pm 1.1 \mathrm{~nm})$ and out-of-plane pore dimensions $(5.8 \pm 0.7$ to $5.7 \pm$ $1.1 \mathrm{~nm})$. In contrast, the presence of the swelling agent resulted in a $40 \%$ increase of both mean in-plane and out of plane pore 
size with $15.8 \pm 1$ and $8.3 \pm 1 \mathrm{~nm}$, respectively (Figure 7C). Table 5 list all the structural parameters calculated for the three samples studied during this work using EP.

Table 5. Pore Diameter $\left(D_{\mathrm{p}}\right)$, Pore Center-to-Center Distance $\left(D_{\mathrm{c}-\mathrm{c}}\right)$, and Porosity Calculated from Analysis of the EP Measures with IIC Model

\begin{tabular}{lccccc} 
sample & $\begin{array}{c}\text { in-plane } \\
D_{c-c}(\mathrm{~nm})\end{array}$ & $\begin{array}{c}\text { out-of-plane } \\
D_{\mathrm{c}-\mathrm{c}}(\mathrm{nm})\end{array}$ & $\begin{array}{c}\text { in-plane } D_{\mathrm{p}} \\
(\mathrm{nm})\end{array}$ & $\begin{array}{c}\text { out-of-plane } \\
D_{\mathrm{p}}(\mathrm{nm})\end{array}$ & $\begin{array}{c}\text { porosity } \\
(\%)\end{array}$ \\
$\mathrm{A}_{10}$ & n.a. & n.a. & $10.7 \pm 1.1$ & $5.7 \pm 1.1$ & 36.2 \\
$\mathrm{~A}_{20}$ & n.a. & n.a. & $10.9 \pm 0.7$ & $5.8 \pm 0.7$ & 50.1 \\
$\mathrm{~A}_{20+\mathrm{HP}}$ & n.a. & n.a. & $15.8 \pm 1$ & $8.3 \pm 1$ & 54.9 \\
\hline
\end{tabular}

For porous networks with narrow restrictions, in the absence of cavitation effects, the desorption isotherm can be used to measure the size of the pore necks using the Kelvin equation as described above. ${ }^{74}$ Accurate analysis of pore interconnections may facilitate the development of materials for mass transport applications, where efficient diffusion of molecules through the porous network is crucial for material performance. ${ }^{12,15}$

Surface Area Determination. The surface area of the mesoporous films can be determined from EP data by applying the Brunauer, Emmett and Teller ${ }^{101}$ (BET) method, widely used in physisorption techniques, to the obtained isotherms. In this approach, the monolayer capacity $\left(V_{\mathrm{BET}}\right)$, defined as the volume of the sorbed gas when the whole surface is covered with a monolayer, is related to the changes in relative pressure by the equation $^{33}$

$$
\frac{p / p^{0}}{V_{\mathrm{ads}}\left(1-p / p^{0}\right)}=\frac{1}{V_{\mathrm{BET}} C}+\frac{C-1}{V_{\mathrm{BET}} C}\left(p / p^{0}\right)
$$

Where $V_{\text {ads }}$ is the volume of gas sorbed at the given relative pressure $p / p^{0}$ and $C$ is the BET constant defined as

$$
C=e^{E_{1}-E_{\mathrm{L}} / R T}
$$

With $E_{1}$ the heat of adsorption of the first monolayer and $E_{\mathrm{L}}$ the heat of evaporation. Mapping eq 7 versus $p / p^{0}$ results in the socalled BET plot, with the slope $\frac{C-1}{V_{\mathrm{BET}} \mathrm{C}}$ and the y-intercept $\frac{1}{V_{\mathrm{BET}} \mathrm{C}}$. Fitting the experimental values to the BET plot in the linear range, which is often limited to $0.05 \leq p / p^{0} \leq 0.3$ for type II and IVa isotherms, ${ }^{33}$ allows for determining $V_{\mathrm{BET}}=\frac{1}{\text { slope }+y \text {. intercept }}$ and $C=1+\frac{\text { slope }}{y \text {.intercept }}$.

The specific surface area $\left(S_{\mathrm{BET}}\right)$ is defined by the BET theory as

$$
S_{\mathrm{BET}}=\frac{\sigma_{\mathrm{m}} N_{\mathrm{A}}}{v_{\mathrm{m}}} \frac{V_{\mathrm{BET}}}{m}
$$

With $\sigma_{\mathrm{m}}$ the effective cross-section area occupied by each molecule in the monolayer, $N_{\mathrm{A}}$ the Avogadro's number, $v_{\mathrm{m}}$ the molar volume of the adsorbed molecules (liquid), and $m$ the mass of the analyzed part of the film. The cross-section area, $\sigma_{\mathrm{m}}$ can be calculated by ${ }^{102}$

$$
\sigma_{\mathrm{m}}=1.091\left(\frac{M_{\mathrm{L}}}{\rho_{\mathrm{L}} N_{\mathrm{A}}}\right)^{2 / 3}
$$

Where $M_{\mathrm{L}}$ and $\rho_{\mathrm{L}}$ are the molar mass and the density of the adsorbed gas, respectively. On the basis of solely the above molecular variables and eq 10 , the cross-sectional areas for water and toluene were determined to be 0.105 and $0.343 \mathrm{~nm}^{2}$, respectively.

Figure 8 shows the BET plot obtained for the mesoporous film $\mathrm{A}_{20}$ analyzed with water and toluene. The corresponding

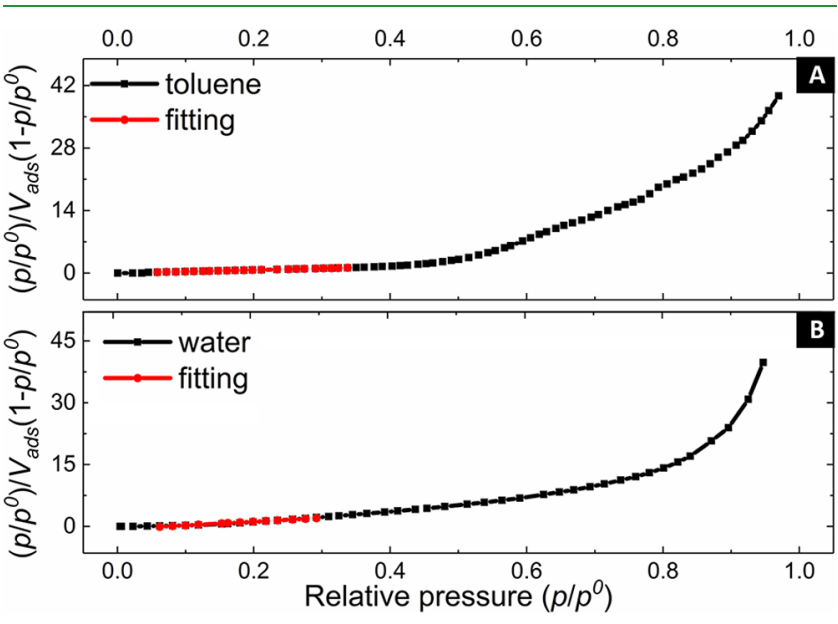

Figure 8. BET plot and fitting of the mesoporous film $\mathrm{A}_{20}$ analyzed with (A) toluene and (B) water as sorbent molecules.

surface area, $S_{\mathrm{BET}}$, determined by the BET method was $418 \mathrm{~m}^{2} /$ $\mathrm{cm}^{3}$ for water and $636 \mathrm{~m}^{2} / \mathrm{cm}^{3}$ for toluene. The difference in the calculated surface area may attributed to the molecular interactions of the water molecules with the surface of the mesopores. These are not considered in eq 10, therefore underestimating the surface area. In our study, the silanol groups on the silica surface ${ }^{103}$ strongly interact with water molecules to form H-bonds, ${ }^{104}$ thus resulting in a higher cross-section $(0.148$ $\mathrm{nm}^{2}$ ) for water molecules adsorbed on silica surfaces. ${ }^{105}$ Following the previous reported adjustment of the crosssectional area for water, a surface area of $589 \mathrm{~m}^{2} / \mathrm{cm}^{3}$ was determined for $A_{20}$, which is similar to the values obtained with toluene.

\section{COMPARATIVE OVERVIEW}

Table 6 presents a summary of the different techniques used during this study and their capabilities toward extracting key porosimetric characteristics. In the following, the techniques will be critically compared for each parameter.

Center-to-Center Pore Distance $D_{c-c}$ (in-Plane and outof-Plane). With respect to the in-plane $D_{c_{-c}}$ only AFM, SEM, and GISAXS were able to provide a result. In contrast, EP does not offer information on the geometric pore arrangement. Both surface imaging techniques, i.e., AFM and SEM, provided very similar results, with discrepancies below 3\%. In direct comparison, the in-plane $D_{c-c}$ calculated from the GISAXS scattering patterns yielded slightly larger $(5-15 \%)$ values for image analysis, but with consistent trends. Importantly, although the mean values for AFM and SEM were obtained by statistical analysis of individual measurements, the GISAXS data relates to a mean characteristic spacing from ensemble scattering. Furthermore, AFM and SEM images only present information on several $\mu \mathrm{m}^{3}$ sample volume on the film surface, GISAXS probes the film in a sample volume several orders of magnitude larger than the characteristic feature sizes, with an interaction volume of the beam at grazing incidence of typically several $\mathrm{mm}^{3}$. Moreover, GISAXS is the only technique that provides quantitative information on the out-of-plane $\mathrm{D}_{\mathrm{c}-\mathrm{c}}$. Although SEM is capable of out-of-plane structural information by cross- 
Table 6. General Summary of the Different Characterization Techniques Presented in This Study, with * Denoting a Limitation to Qualitative Information

\begin{tabular}{|c|c|c|c|c|c|}
\hline \multirow{2}{*}{\multicolumn{2}{|c|}{ measured sample property }} & \multirow{2}{*}{$\frac{\text { AFM }}{\text { sample topography }}$} & \multirow{2}{*}{$\begin{array}{c}\text { SEM } \\
\text { secondary electrons }\end{array}$} & \multirow{2}{*}{$\frac{\text { GISAXS }}{\text { X-ray sample scattering }}$} & \multirow{2}{*}{$\frac{\mathrm{EP}}{\text { refractive index }}$} \\
\hline & & & & & \\
\hline \multirow[t]{6}{*}{ extracted data } & in-plane $D_{c-c}$ & yes & yes & yes & no \\
\hline & out-of-plane $D_{c-c}$ & no & yes* & yes & no \\
\hline & in-plane $D_{p}$ & yes & yes & no & yes \\
\hline & out-of-plane $D_{\mathrm{p}}$ & no & yes* & no & yes \\
\hline & porosity & no & no & yes & yes \\
\hline & surface area & no & no & no & yes \\
\hline \multirow{2}{*}{\multicolumn{2}{|c|}{$\begin{array}{l}\text { section of the film analyzed } \\
\text { analyzed sample volume }\end{array}$}} & surface & surface and cross-section & entire film & entire film \\
\hline & & several $\mu \mathrm{m}^{3}$ & several $\mu \mathrm{m}^{3}$ & several $\mathrm{mm}^{3}$ & several $\mathrm{mm}^{3}$ \\
\hline
\end{tabular}

sectional analysis, this is only of qualitative nature and depends on the viability to cleave a representative area. Importantly, SEM and GISAXS are carried out in a high vacuum environment, and hence sample compatibility needs to be ensured.

Pore Dimensions (in-Plane and out-of-Plane). Only AFM, SEM, and EP were able to provide information on the inplane pore dimension $D_{\mathrm{p}}$. It is important to point out the excellent agreement between the results obtained by the different techniques, well within the margin of error. This may not be valid under all experimental circumstances and sample types. Surface substrate energy and surface segregation can have a dramatic effect on the microstructure of the mesoporous film, making the film surface not necessarily representative of the whole film. ${ }^{106}$ In the case of AFM, lateral dimensions may be strongly distorted because of AFM tip convolution effects. ${ }^{107}$ Although this does not affect the $D_{\mathrm{c}-\mathcal{c}}$ it should be taken into account when $D_{\mathrm{p}}$ is studied. On the other hand, even if ellipsometry may be applied in dry and wet conditions, AFM is the only instrument that can image samples submerged in a liquid with nm-scale resolution. This makes AFM the most appropriate technique for comparative studies between liquid and dry environments. ${ }^{108,109}$ Importantly, EP was the only technique capable to determine the pore anisotropy that originates from film contraction normal to the substrate during calcination processing as well as the pore neck size. This structural information is highly valuable for a number of mesoporous applications, e.g., chemical-/biosensors or separation membranes.

Porosity and Surface Area. Among the four techniques, only GISAXS and EP are able probe the bulk of the film and, thus, offer routes toward assessing the porosity. In the case of GISAXS, the porosity calculation is based on the critical scattering angle of the material and relies on an accurate knowledge of the scattering length density of the scaffold material and substrate. In this study, porosity values around $40 \%$ were obtained for two samples, but no distinct scattering angle was found in the third case. In low- $k$ materials, the critical scattering angle is not easily observed, making the estimation certainly inaccurate. This limitation may be solved with multiple wavelength measurement, but it will increase also the acquisition time and the complexity of the analysis. ${ }^{88}$ Moreover, no information about the accessible porosity or surface area can be acquired by this technique. In contrast, consistent values of porosity were obtained in this study by EP. A significant rise in the porosity was observed with an increase in the organicinorganic ratio from 35 to $50 \%\left(\mathrm{~A}_{10}\right.$ vs $\left.\mathrm{A}_{20}\right)$, whereas only a small further enhancement to $54 \%$ was found with the presence of the swelling agent, which is in agreement with previous observations. ${ }^{28}$ It is important to mention that EP provides information on the accessible porosity as well as the surface area from the EP isotherms, two structural parameters of fundamental importance in many applications of mesoporous films.

\section{CONCLUSIONS}

During this work, some of the most commonly used characterization techniques for porosimetric evaluation of mesoporous thin films have been applied to model samples in a tutorial overview. Although imaging techniques, such as AFM and SEM, provide a straightforward and in our case reliable characterization of surface topology, information about the $3 \mathrm{D}$ pore dimensions and arrangement is often required. GISAXS represents a reliable method to evaluate the $3 \mathrm{D}$ mesostructure, inclusive the pore arrangement, pore spacing, and structural order. However, some restrictions apply, such as the provision of pore size distributions, determination of porosity for low-k materials and information on accessible porosity and surface area. To this end, EP represents one of the most versatile characterization techniques for the porosimetry of thin films, providing quantitative information over pore morphology, pore size distribution, surface area, and overall porosity. Ultimately, the characterization technique(s) of choice will depend on the application in mind and the availability of suitable instrumentation.

\section{ASSOCIATED CONTENT}

SI Supporting Information

The Supporting Information is available free of charge at https://pubs.acs.org/doi/10.1021/acsami.9b17899.

Additional structural analysis results using, AFM, SEM, GISAXS and EP b(PDF)

\section{AUTHOR INFORMATION}

\section{Corresponding Author}

Stefan Guldin - University College London, London, United Kingdom.; 이이이.org/0000-0002-4413-5527; Email: s.guldin@ucl.ac.uk

\section{Other Authors}

Alberto Alvarez-Fernandez - University College London, London, United Kingdom.; (1) orcid.org/0000-00022607-3035

Barry Reid - University College London, London, United Kingdom.; (1) orcid.org/0000-0002-4803-829X

Maximiliano J. Fornerod - University College London, London, United Kingdom.; (1) orcid.org/0000-00016858-299X 
Alaric Taylor - University College London, London, United Kingdom.; (1) orcid.org/0000-0001-6494-8309

Giorgio Divitini - University of Cambridge, Cambridge, United Kingdom; ๑ orcid.org/0000-0003-2775-610X

Complete contact information is available at:

https://pubs.acs.org/10.1021/acsami.9b17899

\section{Notes}

The authors declare no competing financial interest.

\section{ACKNOWLEDGMENTS}

A.A.F., M.J.F., and S.G. acknowledge funding by an EPSRC New Investigator Award (EP/R035105/1). B.R. is grateful for an EPSRC Industrial Case Award (EP/M506448/1) in support of BASF. A.T. recognizes support by the EPSRC Doctoral Training Partnership scheme (EP/M507970/1). G.D. acknowledges funding from the Henry Royce Institute (Grants EP/ P024947/1 and EP/R00661X/1) and the European Union Horizon 2020 research and innovation program under Grant 823717 - ESTEEM3. The authors thank Dr. Han Wu and the EPSRC CNIE research facility service (EPSRC Award, EP/ K038656/1) at University College London for the collection of GISAXS data as well as Dr. Peter Basa and Dr. Bálint Fodor of Semilab (Budapest, Hungary) for carrying out EP measurements with toluene as sorbent.

\section{REFERENCES}

(1) Germain, J.; Hradil, J.; Fréchet, J. M. J.; Svec, F. High Surface Area Nanoporous Polymers for Reversible Hydrogen Storage. Chem. Mater. 2006, 18 (18), 4430-4435.

(2) Krins, N.; Bass, J. D.; Grosso, D.; Henrist, C.; Delaigle, R.; Gaigneaux, E. M.; Cloots, R.; Vertruyen, B.; Sanchez, C. NbVO5Mesoporous Thin Films by Evaporation Induced Micelles Packing: Pore Size Dependence of the Mechanical Stability upon Thermal Treatment and Li Insertion/Extraction. Chem. Mater. 2011, 23 (18), 4124-4131.

(3) Innocenzi, P.; Costacurta, S.; Kidchob, T.; Malfatti, L.; Falcaro, P.; Soler-Illia, G. Mesoporous Thin Films: Properties and Applications. In Thin Films; Springer, Dordrecht, The Netherlands, 2008; pp 105-123.

(4) Wang, P.; Wang, M.; Liu, F.; Ding, S.; Wang, X.; Du, G.; Liu, J.; Apel, P.; Kluth, P.; Trautmann, C.; Wang, Y. Ultrafast Ion Sieving Using Nanoporous Polymeric Membranes. Nat. Commun. 2018, 9 (1), 569.

(5) Jackson, E. A.; Hillmyer, M. A. Nanoporous Membranes Derived from Block Copolymers: From Drug Delivery to Water Filtration. ACS Nano 2010, 4, 3548-3553.

(6) Nunes, S. P. Block Copolymer Membranes for Aqueous Solution Applications. Macromolecules 2016, 49, 2905-2916.

(7) Haque, M. A.; Sheikh, A. D.; Guan, X.; Wu, T. Metal Oxides as Efficient Charge Transporters in Perovskite Solar Cells. Adv. Energy Mater. 2017, 7 (20), 1602803.

(8) Guldin, S.; Hüttner, S.; Kolle, M.; Welland, M. E.; MüllerBuschbaum, P.; Friend, R. H.; Steiner, U.; Tétreault, N. Dye-Sensitized Solar Cell Based on a Three-Dimensional Photonic Crystal. Nano Lett. 2010, 10 (7), 2303-2309.

(9) Guldin, S.; Hüttner, S.; Tiwana, P.; Orilall, M. C.; Ülgüt, B.; Stefik, M.; Docampo, P.; Kolle, M.; Divitini, G.; Ducati, C.; Redfern, S. A. T.; Snaith, H. J.; Wiesner, U.; Eder, D.; Steiner, U. Improved Conductivity in Dye-Sensitised Solar Cells through Block-Copolymer Confined TiO 2 Crystallisation. Energy Environ. Sci. 2011, 4 (1), 225-233.

(10) RoyChaudhuri, C. A Review on Porous Silicon Based Electrochemical Biosensors: Beyond Surface Area Enhancement Factor. Sens. Actuators, B 2015, 210, 310-323.

(11) Mizoshita, N.; Tani, T.; Inagaki, S. Syntheses, Properties and Applications of Periodic Mesoporous Organosilicas Prepared from Bridged Organosilane Precursors. Chem. Soc. Rev. 2011, 40 (2), 789800 .
(12) Alberti, S.; Steinberg, P. Y.; Giménez, G.; Amenitsch, H.; Ybarra, G.; Azzaroni, O.; Angelomé, P. C.; Soler-Illia, G. J. A. A. Chemical Stability of Mesoporous Oxide Thin Film Electrodes under Electrochemical Cycling: From Dissolution to Stabilization. Langmuir 2019, 35 (19), 6279-6287.

(13) Bearzotti, A.; Bertolo, J. M.; Innocenzi, P.; Falcaro, P.; Traversa, E. Humidity Sensors Based on Mesoporous Silica Thin Films Synthesised by Block Copolymers. J. Eur. Ceram. Soc. 2004, 24 (6), 1969-1972.

(14) Reta, N.; Saint, C. P.; Michelmore, A.; Prieto-Simon, B.; Voelcker, N. H. Nanostructured Electrochemical Biosensors for LabelFree Detection of Water- and Food-Borne Pathogens. ACS Appl. Mater. Interfaces 2018, 10, 6055-6072.

(15) Lian, H. Y.; Liang, Y. H.; Yamauchi, Y.; Wu, K. C.-W. A Hierarchical Study on Load/Release Kinetics of Guest Molecules into/ from Mesoporous Silica Thin Films. J. Phys. Chem. C 2011, 115 (14), 6581-6590.

(16) Stefik, M.; Guldin, S.; Vignolini, S.; Wiesner, U.; Steiner, U. Block Copolymer Self-Assembly for Nanophotonics. Chem. Soc. Rev. 2015, 44 (15), 5076-5091.

(17) Guldin, S.; Kohn, P.; Stefik, M.; Song, J.; Divitini, G.; Ecarla, F.; Ducati, C.; Wiesner, U.; Steiner, U. Self-Cleaning Antireflective Optical Coatings. Nano Lett. 2013, 13 (11), 5329-5335.

(18) Thomas, I. M. Method for the Preparation of Porous Silica Antireflection Coatings Varying in Refractive Index from 122 to 144. Appl. Opt. 1992, 31 (28), 6145.

(19) Xi, J. Q.; Schubert, M. F.; Kim, J. K.; Schubert, E. F.; Chen, M.; Lin, S. Y.; Liu, W.; Smart, J. A. Optical Thin-Film Materials with Low Refractive Index for Broadband Elimination of Fresnel Reflection. Nat. Photonics 2007, 1 (3), 176-179.

(20) Lee, D.; Rubner, M. F.; Cohen, R. E. All-Nanoparticle Thin-Film Coatings. Nano Lett. 2006, 6 (10), 2305-2312.

(21) Scherer, M. R. J.; Li, L.; Cunha, P. M. S.; Scherman, O. A.; Steiner, U. Enhanced Electrochromism in Gyroid-Structured Vanadium Pentoxide. Adv. Mater. 2012, 24 (9), 1217-1221.

(22) Crossland, E. J. W.; Kamperman, M.; Nedelcu, M.; Ducati, C.; Wiesner, U.; Smilgies, D.-M.; Toombes, G. E. S.; Hillmyer, M. A.; Ludwigs, S.; Steiner, U.; Snaith, H. J. A Bicontinuous Double Gyroid Hybrid Solar Cell. Nano Lett. 2009, 9 (8), 2807-2812.

(23) Park, C.; Yoon, J.; Thomas, E. L. Enabling Nanotechnology with Self Assembled Block Copolymer Patterns. Polymer 2003, 44, 67256760.

(24) Grosso, D.; Cagnol, F.; Soler-Illia, G. J. D. A. A.; Crepaldi, E. L.; Amenitsch, H.; Brunet-Bruneau, A.; Bourgeois, A.; Sanchez, C. Fundamentals of Mesostructuring through Evaporation-Induced SelfAssembly. Adv. Funct. Mater. 2004, 14, 309-322.

(25) Alberius, P. C. A.; Frindell, K. L.; Hayward, R. C.; Kramer, E. J.; Stucky, G. D.; Chmelka, B. F. General Predictive Syntheses of Cubic, Hexagonal, and Lamellar Silica and Titania Mesostructured Thin Films. Chem. Mater. 2002, 14 (8), 3284-3294.

(26) Crepaldi, E. L.; Soler-Illia, G. J. d. A. A.; Grosso, D.; Cagnol, F.; Ribot, F.; Sanchez, C. Controlled Formation of Highly Organized Mesoporous Titania Thin Films: From Mesostructured Hybrids to Mesoporous Nanoanatase TiO2. J. Am. Chem. Soc. 2003, 125 (32), 9770-9786.

(27) Nedelcu, M.; Lee, J.; Crossland, E. J. W.; Warren, S. C.; Orilall, M. C.; Guldin, S.; Hüttner, S.; Ducati, C.; Eder, D.; Wiesner, U.; Steiner, U.; Snaith, H. J. Block Copolymer Directed Synthesis of Mesoporous TiO2 for Dye-Sensitized Solar Cells. Soft Matter 2009, 5 (1), 134-139.

(28) Lokupitiya, H. N.; Jones, A.; Reid, B.; Guldin, S.; Stefik, M. Ordered Mesoporous to Macroporous Oxides with Tunable Isomorphic Architectures: Solution Criteria for Persistent Micelle Templates. Chem. Mater. 2016, 28 (6), 1653-1667.

(29) Hatton, B.; Mishchenko, L.; Davis, S.; Sandhage, K. H.; Aizenberg, J. Assembly of Large-Area, Highly Ordered, Crack-Free Inverse Opal Films. Proc. Natl. Acad. Sci. U. S. A. 2010, 107 (23), 10354-10359. 
(30) Dewar, J. The Absorption and Thermal Evolution of Gases Occluded in Charcoal at Low Temperatures. Proc. R. Soc. London 1904, 74, 122-127.

(31) Ramsay, W. A Determination of the Amounts of Neon and Helium in Atmospheric Air. Proc. R. Soc. London, Ser. A 1905, 76 (508), 111-114.

(32) Krause, K. M.; Taschuk, M. T.; Harris, K. D.; Rider, D. A.; Wakefield, N. G.; Sit, J. C.; Buriak, J. M.; Thommes, M.; Brett, M. J. Surface Area Characterization of Obliquely Deposited Metal Oxide Nanostructured Thin Films. Langmuir 2010, 26 (6), 4368-4376.

(33) Thommes, M.; Kaneko, K.; Neimark, A. V.; Olivier, J. P.; Rodriguez-Reinoso, F.; Rouquerol, J.; Sing, K. S. W. Physisorption of Gases, with Special Reference to the Evaluation of Surface Area and Pore Size Distribution (IUPAC Technical Report). Pure Appl. Chem. 2015, 87 (9-10), 1051-1069.

(34) Zhang, W.; Qu, Z.; Li, X.; Wang, Y.; Ma, D.; Wu, J. Comparison of Dynamic Adsorption/Desorption Characteristics of Toluene on Different Porous Materials. J. Environ. Sci. 2012, 24 (3), 520-528.

(35) Ricco, A. J.; Frye, G. C.; Martin, S. J. Determination of BET Surface Areas of Porous Thin Films Using Surface Acoustic Wave Devices. Langmuir 1989, 5 (1), 273-276.

(36) Gregg, S. J.; Sidney, J.; Sing, K. S. W. Adsorption, Surface Area, and Porosity; Academic Press, 1982.

(37) Hietala, S. L.; Smith, D. M.; Hietala, V. M.; Frye, G. C.; Martin, S. J. Pore Structure Characterization of Thin Films Using a Surface Acoustic Wave/Volumetric Adsorption Technique. Langmuir 1993, 9 (1), 249-251.

(38) Freer, E. M.; Krupp, L. E.; Hinsberg, W. D.; Rice, P. M.; Hedrick, J. L.; Cha, J. N.; Miller, R. D.; Kim, H. C. Oriented Mesoporous Organosilicate Thin Films. Nano Lett. 2005, 5 (10), 2014-2018.

(39) Guldin, S.; Kolle, M.; Stefik, M.; Langford, R.; Eder, D.; Wiesner, U.; Steiner, U. Tunable Mesoporous Bragg Reflectors Based on BlockCopolymer Self-Assembly. Adv. Mater. 2011, 23 (32), 3664-3668.

(40) Ma, Y.; Zhang, Y.; Han, L.; Che, S.; Terasaki, O. Structure Characterization of Mesoporous Materials by Electron Microscopy. Enzymes 2018, 43, 11-30.

(41) Alvarez-Fernandez, A.; Valdes-Vango, F.; Martín, J. I.; Vélez, M.; Quirós, C.; Hermida-Merino, D.; Portale, G.; Alameda, J. M.; García Alonso, F. J. Tailoring Block Copolymer Nanoporous Thin Films with Acetic Acid as a Small Guest Molecule. Polym. Int. 2019, 68 (11), 1914-1920.

(42) Álvarez-Fernández, A.; Valdés-Bango, F.; Losada-Ambrinos, R.; Martín, J. I.; Vélez, M.; Alameda, J. M.; García Alonso, F. J. Polymer Porous Thin Films Obtained by Direct Spin Coating. Polym. Int. 2018, 67 (4), 393-398.

(43) Brenner, A. M.; Adkins, B. D.; Spooner, S.; Davis, B. H. Porosity by Small-Angle X-Ray Scattering (SAXS): Comparison with Results from Mercury Penetration and Nitrogen Adsorption. J. Non-Cryst. Solids 1995, 185 (1-2), 73-77.

(44) Radlinski, A. P.; Mastalerz, M.; Hinde, A. L.; Hainbuchner, M.; Rauch, H.; Baron, M.; Lin, J. S.; Fan, L.; Thiyagarajan, P. Application of SAXS and SANS in Evaluation of Porosity, Pore Size Distribution and Surface Area of Coal. Int. J. Coal Geol. 2004, 59 (3-4), 245-271.

(45) Lin, B.; Döbeli, M.; Mudie, S.; Hawley, A.; Hodgson, P.; Kong, L.; Spolenak, R.; Dumée, L. F. An In-Situ Small Angle x Ray Scattering Analysis of Nanopore Formation during Thermally Induced Chemical Dealloying of Brass Thin Foils. Sci. Rep. 2018, 8 (1), 15419.

(46) Levine, J. R.; Cohen, J. B.; Chung, Y. W.; Georgopoulos, P. Grazing-Incidence Small-Angle X-Ray Scattering: New Tool for Studying Thin Film Growth. J. Appl. Crystallogr. 1989, 22 (6), 528532.

(47) Hexemer, A.; Müller-Buschbaum, P. Advanced GrazingIncidence Techniques for Modern Soft-Matter Materials Analysis. IUCrJ 2015, 2 (1), 106-125.

(48) Müller-Buschbaum, P. Grazing Incidence Small-Angle X-Ray Scattering: An Advanced Scattering Technique for the Investigation of Nanostructured Polymer Films. Anal. Bioanal. Chem. 2003, 376 (1), 310.
(49) Panduro, E. A. C.; Granlund, H.; Sztucki, M.; Konovalov, O.; Breiby, D. W.; Gibaud, A. Using Three-Dimensional 3D GrazingIncidence Small-Angle X-Ray Scattering (GISAXS) Analysis To Probe Pore Deformation in Mesoporous Silica Films. ACS Appl. Mater. Interfaces 2014, 6 (4), 2686-2691.

(50) Sarkar, A.; Stefik, M. How to Make Persistent Micelle Templates in $24 \mathrm{~h}$ and Know It Using X-Ray Scattering. J. Mater. Chem. A 2017, 5 (23), 11840-11853.

(51) Ortel, E.; Hertwig, A.; Berger, D.; Esposito, P.; Rossi, A. M.; Kraehnert, R.; Hodoroaba, V.-D. New Approach on Quantification of Porosity of Thin Films via Electron-Excited X-Ray Spectra. Anal. Chem. 2016, 88 (14), 7083-7090.

(52) Patterson, B. M.; DeFriend Obrey, K. A.; Hamilton, C. E.; Havrilla, G. J. Three-Dimensional Density Measurements of Ultra Low Density Materials by X-Ray Scatter Using Confocal Micro X-Ray Fluorescence Spectroscopy. X-Ray Spectrom. 2012, 41 (4), 253-258.

(53) Cordes, N. L.; Havrilla, G. J.; Usov, I. O.; Obrey, K. A.; Patterson, B. M. Non-Destructive Elemental Quantification of PolymerEmbedded Thin Films Using Laboratory Based X-Ray Techniques. Spectrochim. Acta, Part B 2014, 101, 320-329.

(54) Petkov, M. P.; Wang, C. L.; Weber, M. H.; Lynn, K. G.; Rodbell, K. P. Positron Annihilation Techniques Suited for Porosity Characterization of Thin Films. J. Phys. Chem. B 2003, 107 (12), 2725-2734.

(55) Dull, T. L.; Frieze, W. E.; Gidley, D. W.; Sun, J. N.; Yee, A. F. Determination of Pore Size in Mesoporous Thin Films from the Annihilation Lifetime of Positronium. J. Phys. Chem. B 2001, 105 (20), 4657-4662.

(56) Rouessac, V.; van der Lee, A.; Bosc, F.; Durand, J.; Ayral, A. Three Characterization Techniques Coupled with Adsorption for Studying the Nanoporosity of Supported Films and Membranes. Microporous Mesoporous Mater. 2008, 111 (1-3), 417-428.

(57) Sanchez, C.; Boissière, C.; Grosso, D.; Laberty, C.; Nicole, L. Design, Synthesis, and Properties of Inorganic and Hybrid Thin Films Having Periodically Organized Nanoporosity. Chem. Mater. 2008, 20 (3), 682-737.

(58) Hedden, R. C.; Lee, H. J.; Soles, C. L.; Bauer, B. J. Characterization of Pore Structure in a Nanoporous Low-DielectricConstant Thin Film by Neutron Porosimetry and X-Ray Porosimetry. Langmuir 2004, 20 (16), 6658-6667.

(59) Lee, H. J.; Soles, C. L.; Liu, D. W.; Bauer, B. J.; Wu, W. L. Pore Size Distributions in Low-k Dielectric Thin Films from X-Ray Porosimetry. J. Polym. Sci., Part B: Polym. Phys. 2002, 40 (19), 21702177.

(60) Wu, W. L.; Wallace, W. E.; Lin, E. K.; Lynn, G. W.; Glinka, C. J.; Ryan, E. T.; Ho, H. M. Properties of Nanoporous Silica Thin Films Determined by High-Resolution $\mathrm{x}$-Ray Reflectivity and Small-Angle Neutron Scattering. J. Appl. Phys. 2000, 87 (3), 1193-1200.

(61) Mogilnikov, K. P.; Polovinkin, V. G.; Dultsev, F. N.; Baklanov, M. R. Calculation of Pore Size Distribution in the Ellipsometric Porosimetry: Method and Reliability. Mater. Res. Soc. Symp. - Proc. $1999,565,81-86$.

(62) Baklanov, M. R.; Mogilnikov, K. P.; Polovinkin, V. G.; Dultsev, F. N. Determination of Pore Size Distribution in Thin Films by Ellipsometric Porosimetry. J. Vac. Sci. Technol., B: Microelectron. Process. Phenom. 2000, 18 (3), 1385-1391.

(63) Boissiere, C.; Grosso, D.; Lepoutre, S.; Nicole, L.; Bruneau, A. B.; Sanchez, C. Porosity and Mechanical Properties of Mesoporous Thin Films Assessed by Environmental Ellipsometric Porosimetry. Langmuir 2005, 21 (26), 12362-12371.

(64) Mogilnikov, K. P.; Baklanov, M. R. Determination of Young's Modulus of Porous Low-k Films by Ellipsometric Porosimetry. Electrochem. Solid-State Lett. 2002, 5 (12), F29.

(65) Wang, S.; Tangvijitsakul, P.; Qiang, Z.; Bhaway, S. M.; Lin, K.; Cavicchi, K. A.; Soucek, M. D.; Vogt, B. D. Role of Amphiphilic Block Copolymer Composition on Pore Characteristics of MicelleTemplated Mesoporous Cobalt Oxide Films. Langmuir 2016, 32 (16), 4077-4085.

(66) Saxena, R.; Rodriguez, O.; Cho, W.; Gill, W. N.; Plawsky, J. L.; Baklanov, M. R.; Mogilnikov, K. P. Internal Matrix Structure of Low- $\kappa$ 
Mesoporous Silica and Its Relation to Mechanical Properties. J. NonCryst. Solids 2004, 349, 189-199.

(67) Vayer, M.; Nguyen, T. H.; Grosso, D.; Boissiere, C.; Hillmyer, M. A.; Sinturel, C. Characterization of Nanoporous Polystyrene Thin Films by Environmental Ellipsometric Porosimetry. Macromolecules 2011, 44 (22), 8892-8897.

(68) Protasova, L. N.; Rebrov, E. V.; Ismagilov, Z. R.; Schouten, J. C. Determination of the Tolman Length in the Improved DerjaguinBroekhoff-de Boer Theory for Capillary Condensation of Ethanol in Mesoporous Thin Films by Ellipsometric Porosimetry. Microporous Mesoporous Mater. 2009, 123 (1-3), 243-252.

(69) Li, R.; Faustini, M.; Boissière, C.; Grosso, D. Water Capillary Condensation Effect on the Photocatalytic Activity of Porous TiO2 in Air. J. Phys. Chem. C 2014, 118 (31), 17710-17716.

(70) Templin, M.; Franck, A.; Du Chesne, A.; Leist, H.; Zhang, Y.; Ulrich, R.; Schädler, V.; Wiesner, U. Organically Modified Aluminosilicate Mesostructures from Block Copolymer Phases. Science 1997, 278, 1795-1798.

(71) Graberg, T. v.; Hartmann, P.; Rein, A.; Gross, S.; Seelandt, B.; Roger, C.; Zieba, R.; Traut, A.; Wark, M.; Janek, J.; Smarsly, B. M; et al. Mesoporous Tin-Doped Indium Oxide Thin Films: Effect of Mesostructure on Electrical Conductivity. Sci. Technol. Adv. Mater. 2011, 12 (2), 025005

(72) Reid, B.; Taylor, A.; Alvarez-Fernandez, A.; Ismael, M. H.; Sharma, S.; Schmidt-Hansberg, B.; Guldin, S. Photocatalytic Template Removal by Non-Ozone-Generating UV Irradiation for the Fabrication of Well-Defined Mesoporous Inorganic Coatings. ACS Appl. Mater. Interfaces 2019, 11 (21), 19308-19314.

(73) Reid, B.; Taylor, A.; Chen, Y.; Schmidt-Hansberg, B.; Guldin, S. Robust Operation of Mesoporous Antireflective Coatings under Variable Ambient Conditions. ACS Appl. Mater. Interfaces 2018, 10 (12), 10315-10321.

(74) Reid, B.; Alvarez-Fernandez, A.; Schmidt-Hansberg, B.; Guldin, S. Tuning Pore Dimensions of Mesoporous Inorganic Films by Homopolymer Swelling. Langmuir 2019, 35 (43), 14074-14082.

(75) Mondini, S.; Ferretti, A. M.; Puglisi, A.; Ponti, A. Pebbles and PebbleJuggler: Software for Accurate, Unbiased, and Fast Measurement and Analysis of Nanoparticle Morphology from Transmission Electron Microscopy (TEM) Micrographs. Nanoscale 2012, 4 (17), 5356.

(76) Babonneau, D. FitGISAXS: Software Package for Modelling and Analysis of GISAXS Data Using IGOR Pro. J. Appl. Crystallogr. 2010, 43 (4), 929-936

(77) Schneider, C. A.; Rasband, W. S.; Eliceiri, K. W. NIH Image to ImageJ: 25 Years of Image Analysis. Nat. Methods 2012, 9, 671-675.

(78) Allen, C. R.; Yung, N. Vision Assistant Software: A Practical Introduction to Image Processing and Pattern Classifiers; Chapman \& Hall, 1995.

(79) Stevens, R. M. D.; Frederick, N. A.; Smith, B. L.; Morse, D. E.; Stucky, G. D.; Hansma, P. K. Carbon Nanotubes as Probes for Atomic Force Microscopy. Nanotechnology 2000, 11 (1), 1-5.

(80) Kranz, C. Diamond as Advanced Material for Scanning Probe Microscopy Tips. Electroanalysis 2016, 28 (1), 35-45.

(81) Renaud, G.; Lazzari, R.; Leroy, F. Probing Surface and Interface Morphology with Grazing Incidence Small Angle X-Ray Scattering. Surf. Sci. Rep. 2009, 64, 255-380.

(82) Hamley, I. W.; Castelletto, V. Small-Angle Scattering of Block Copolymers in the Melt, Solution and Crystal States. Prog. Polym. Sci. 2004, 29, 909-948.

(83) Thomas, A.; Schlaad, H.; Smarsly, B.; Antonietti, M. Replication of Lyotropic Block Copolymer Mesophases into Porous Silica by Nanocasting: Learning about Finer Details of Polymer Self-Assembly. Langmuir 2003, 19 (10), 4455-4459.

(84) Chourou, S. T.; Sarje, A.; Li, X. S.; Chan, E. R.; Hexemer, A. HipGISAXS: A High-Performance Computing Code for Simulating Grazing-Incidence X-Ray Scattering Data. J. Appl. Crystallogr. 2013, 46 (6), 1781-1795.

(85) Lazzari, R. IsGISAXS: A Program for Grazing-Incidence SmallAngle X-Ray Scattering Analysis of Supported Islands. J. Appl. Crystallogr. 2002, 35 (4), 406-421.
(86) Tanaka, S.; Katayama, Y.; Tate, M. P.; Hillhouse, H. W.; Miyake, Y. Fabrication of Continuous Mesoporous Carbon Films with FaceCentered Orthorhombic Symmetry through a Soft Templating Pathway. J. Mater. Chem. 2007, 17 (34), 3639-3645.

(87) Rawolle, M.; Sarkar, K.; Niedermeier, M. A.; Schindler, M.; Lellig, P.; Gutmann, J. S.; Moulin, J. F.; Haese-Seiller, M.; Wochnik, A. S.; Scheu, C.; Müller-Buschbaum, P. Infiltration of Polymer HoleConductor into Mesoporous Titania Structures for Solid-State DyeSensitized Solar Cells. ACS Appl. Mater. Interfaces 2013, 5 (3), 719729.

(88) Kaune, G.; Haese-Seiller, M.; Kampmann, R.; Moulin, J. F.; Zhong, Q.; Müller-Buschbaum, P. Tof-Gisans Investigation of Polymer Infiltration in Mesoporous TiO 2 Films for Photovoltaic Applications. J. Polym. Sci., Part B: Polym. Phys. 2010, 48 (14), 1628-1635.

(89) Hexemer, A.; Müller-Buschbaum, P. Advanced GrazingIncidence Techniques for Modern Soft-Matter Materials Analysis. IUCrJ 2015, 2 (1), 106-125.

(90) De Paul, S. M.; Zwanziger, J. W.; Ulrich, R.; Wiesner, U.; Spiess, H. W. Structure, Mobility, and Interface Characterization of SelfOrganized Organic-Inorganic Hybrid Materials by Solid-State NMR. J. Am. Chem. Soc. 1999, 121 (24), 5727-5736.

(91) Panduro, E. A. C.; Granlund, H.; Sztucki, M.; Konovalov, O.; Breiby, D. W.; Gibaud, A. Using Three-Dimensional 3D GrazingIncidence Small-Angle X-Ray Scattering (GISAXS) Analysis to Probe Pore Deformation in Mesoporous Silica Films. ACS Appl. Mater. Interfaces 2014, 6 (4), 2686-2691.

(92) Boissiere, C.; Grosso, D.; Lepoutre, S.; Nicole, L.; Bruneau, A. B.; Sanchez, C. Porosity and Mechanical Properties of Mesoporous Thin Films Assessed by Environmental Ellipsometric Porosimetry. Langmuir 2005, 21 (26), 12362-12371.

(93) Boissiere, C.; Brubach, J. B.; Mermet, A.; de Marzi, G.; Bourgaux, C.; Prouzet, E.; Roy, P. Water Confined in Lamellar Structures of AOT Surfactants: An Infrared Investigation. J. Phys. Chem. B 2002, 106 (5), $1032-1035$

(94) Yamaguchi, T.; Hashi, H.; Kittaka, S. X-Ray Diffraction Study of Water Confined in Activated Carbon Pores over a Temperature Range of 228-298 K. J. Mol. Liq. 2006, 129 (1-2), 57-62.

(95) Baklanov, M.; Green, M.; Maex, K. Dielectric Films for Advanced Microelectronics; Baklanov, M. R., Green, M. L., Maex, K., Eds.; John Wiley \& Sons, Ltd.: Chichester, U.K., 2007.

(96) Thommes, M. Physical Adsorption Characterization of Nanoporous Materials. Chem. Ing. Tech. 2010, 82 (7), 1059-1073.

(97) Ravikovitch, P. I.; Neimark, A. V. Density Functional Theory Model of Adsorption on Amorphous and Microporous Silica Materials. Langmuir 2006, 22 (26), 11171-11179.

(98) Barrett, E. P.; Joyner, L. G.; Halenda, P. P. The Determination of Pore Volume and Area Distributions in Porous Substances. I. Computations from Nitrogen Isotherms. J. Am. Chem. Soc. 1951, 73 (1), 373-380.

(99) Gregg, S. J.; Sing, K. S. W. Adsorption, Surface Area and Porosity 1982, 86 (10), 957.

(100) Revol, P.; Perret, D.; Bertin, F.; Fusalba, F.; Rouessac, V.; Chabli, A.; Passemard, G.; Ayral, A. Porosimetry Measurements on Low Dielectric Constant-Thin Layers by Coupling Spectroscopic Ellipsometry and Solvent Adsorption-Desorption. J. Porous Mater. 2005, 12 (2), 113-121.

(101) Brunauer, S.; Emmett, P. H.; Teller, E. Adsorption of Gases in Multimolecular Layers. J. Am. Chem. Soc. 1938, 60 (2), 309-319.

(102) Emmett, P. H.; Brunauer, S. The Use of Low Temperature van Der Waals Adsorption Isotherms in Determining the Surface Area of Iron Synthetic Ammonia Catalysts. J. Am. Chem. Soc. 1937, 59 (8), $1553-1564$

(103) Hair, M. L. Hydroxyl Groups on Silica Surface. J. Non-Cryst. Solids 1975, 19 (C), 299-309.

(104) Hertl, W.; Hair, M. L. Adsorption of Water on Silica. Nature 1969, 223 (5211), 1150-1151.

(105) Lange, K. R. The Characterization of Molecular Water on Silica Surfaces. J. Colloid Sci. 1965, 20 (3), 231-240. 
(106) Epps, T. H.; DeLongchamp, D. M.; Fasolka, M. J.; Fischer, D. A.; Jablonski, E. L. Substrate Surface Energy Dependent Morphology and Dewetting in an ABC Triblock Copolymer Film. Langmuir 2007, 23 (6), 3355-3362.

(107) Wong, C.; West, P. E.; Olson, K. S.; Mecartney, M. L.; Starostina, N. Tip Dilation and AFM Capabilities in the Characterization of Nanoparticles. JOM 2007, 59 (1), 12-16.

(108) Kulkarni, S. A.; Lyles, V. D.; Serem, W. K.; Lu, L.; Kumar, R.; Garno, J. C. Solvent-Responsive Properties of Octadecyltrichlorosiloxane Nanostructures Investigated Using Atomic Force Microscopy in Liquid. Langmuir 2014, 30 (19), 5466-5473.

(109) Gensel, J.; Dewald, I.; Erath, J.; Betthausen, E.; Müller, A. H. E.; Fery, A. Reversible Swelling Transitions in Stimuli-Responsive Layerby-Layer Films Containing Block Copolymer Micelles. Chem. Sci. 2013, $4(1), 325-334$.

\section{NOTE ADDED AFTER ASAP PUBLICATION}

Due to a production error, this paper was published on the Web on January 21, 2020, with missing information in column 3 of Table 2 and column 6 of Table 4 . The corrected version was reposted on January 21, 2020. 